\title{
A Review of Particulate Matter and Health: Focus on Developing Countries
}

Lily Panyacosit

\section{Approved by}

Markus Amann

Project Leader

Transboundary Air Pollution Project

May 2000 Institute, its National Member Organizations, or other organizations supporting the work. 


\section{Contents}

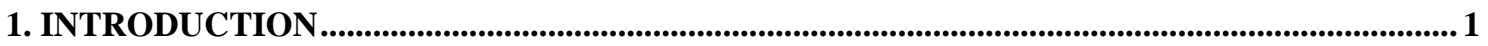

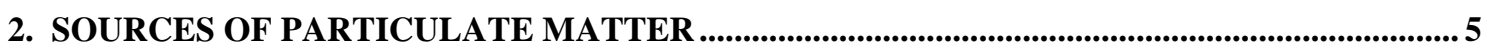

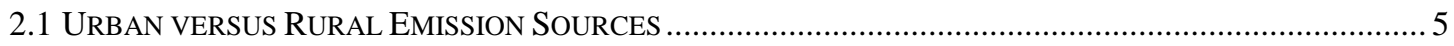

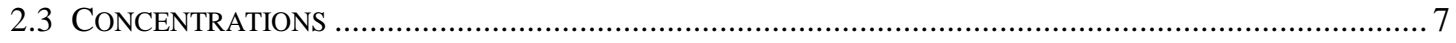

2.3.1 PM Concentrations and Measurements …………................................................................ 7

2.3.2 PM Concentrations in Developing Countries ……................................................................... 8

3. EXPOSURE-RESPONSE.................................................................................................................... 11

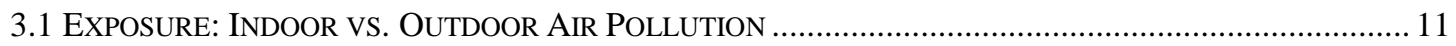

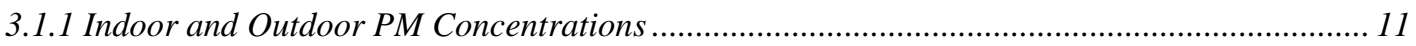

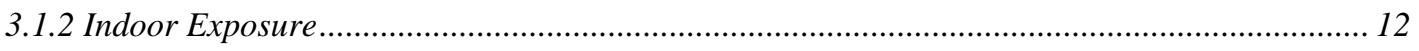

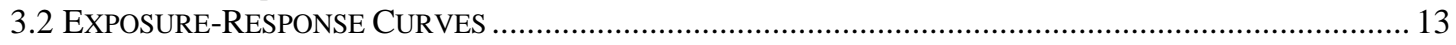

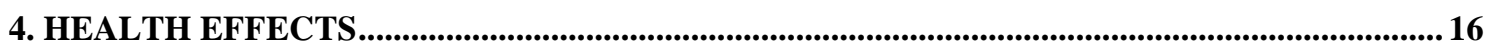

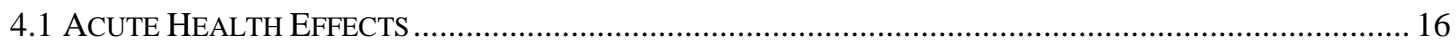

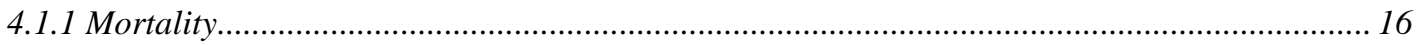

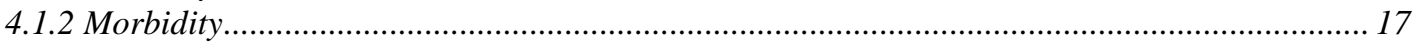

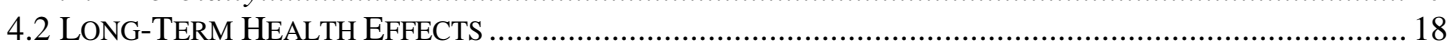

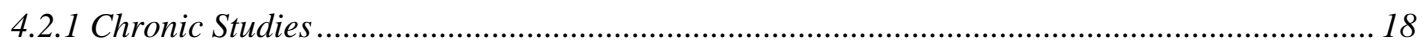

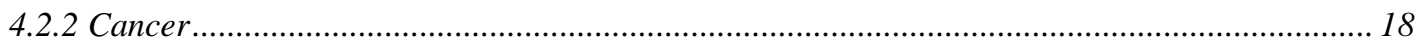

4.3 INDOOR AIR Pollution ReLATEd HEalth EFFECTS ................................................................... 19

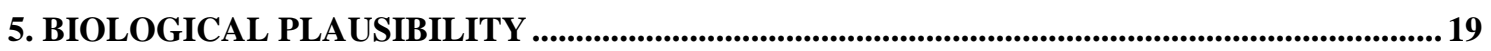

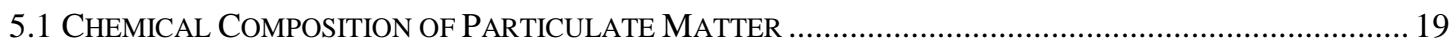

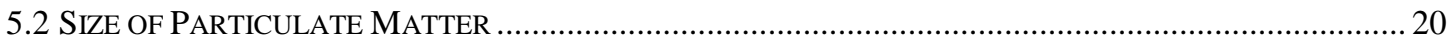

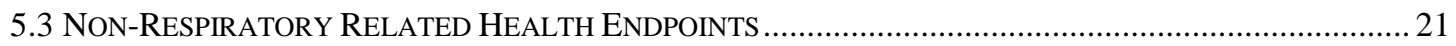

6. COSTS OF AIR POLLUTION ............................................................................................................. 21

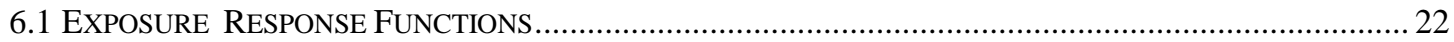

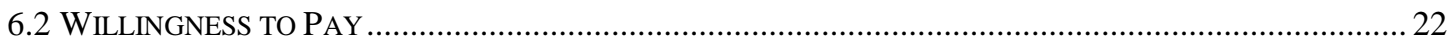

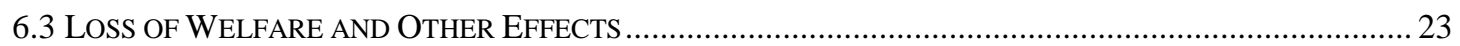

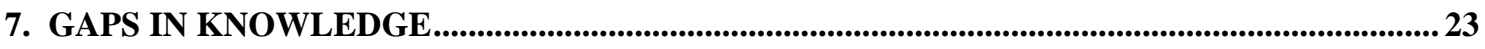

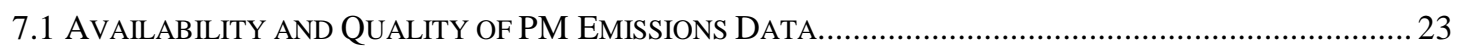

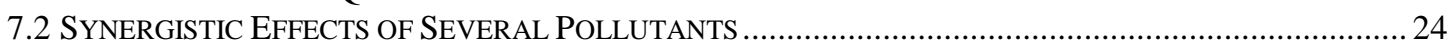

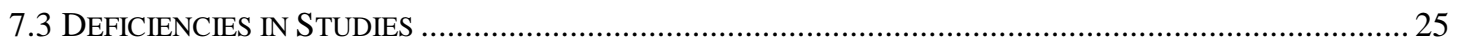

7.3.1 Dearth of Chronic Exposure Studies................................................................................... 25

7.3.2 Provision for Additional Stress in Developing Countries ........................................................ 25

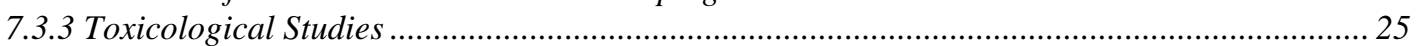

7.4 VALIDITY OF EXTRAPOLATING DATA FROM DEVELOPED COUNTRIES .............................................. 26

7.5. COSTS OF AIR POLLUTION ………………………………………………………………..... 27

8. CONCLUSION

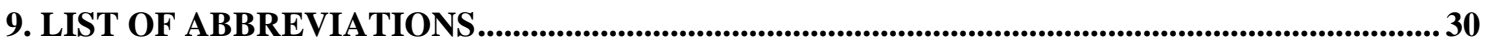




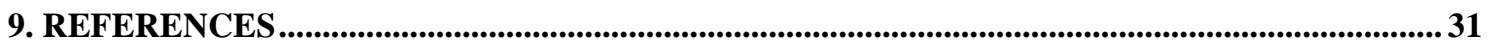

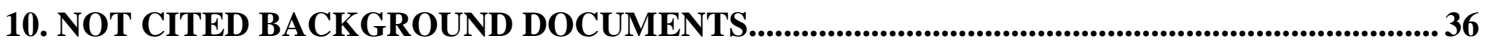

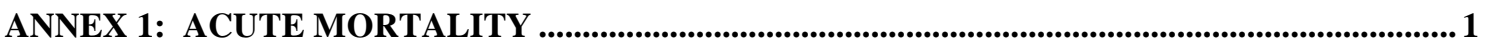

ANNEX 2: ACUTE MORBIDITY ......................................................................................................... 2

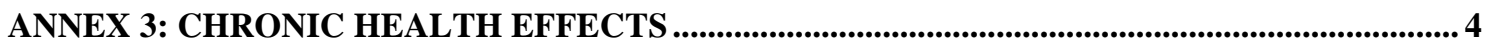

ANNEX 4: INDOOR POLLUTION ...............................................................................................................5 


\section{Abstract}

The burden of ill human health attributable to particulate air pollution is a critical problem of growing concern. In developing countries it is not uncommon to experience today the same particulate matter levels that characterized the devastating "London fog episodes" of the 1950s which resulted in over 4000 cases of premature mortality and countless cases of exacerbated morbidity related health endpoints.

This literature review gives an overview of the situation in developing countries by synthesizing the pertinent information relating to source and concentration of particulate matter, to exposure-response curves, the observed health effects, the plausibility of biological mechanisms, and health related costs. The feasibility of extrapolating data derived from developed countries to estimate health effects for developing countries is briefly considered.

There is little doubt that particulate matter causes or contributes to premature mortality and morbidity related health endpoints in developing countries. Only the most easily observed and quantified health effects have been identified to date. There is increasing proof that the most harmful effects of particulate matter are related to the size of the particle, as particles decrease in size, they are hypothesized to either increase in acidity or in their ability to penetrate into the lower airways.

Even more than in developed countries, personal exposure to particulate matter in developing countries has been found to be badly represented by ambient monitors. Additionally, it may be much more depending on indoor sources and housing types than in developed countries.

Previous studies on costs of particulate air pollution to society in developing countries are rare, and many different approaches have been used. They do not account for loss of welfare, disutility or loss of productivity, which may cause the greatest costs. Thoughts have been given to use the Disability Adjusted Life Year (DALY) to assess health costs for a certain disease and for a given population. DALYs would allow for comparable measures of health costs or benefits to be quantified and compared across populations and regions of the world. 


\section{Acknowledgments}

This work was carried out at the International Institute for Applied Systems Analysis during the Young Scientists Summer Program (YSSP) 1999. I would like to thank the entire TAP project, especially Markus Amann, for their interest and support in my work. Moreover, I would like to thank Anke Lükewille for her continued encouragement and assistance in my work. Special thanks as well to Gordon J. MacDonald for his advice and guidance. I would finally also like to acknowledge the USA NMO for their financial support. 


\section{About the Authors}

Lily Panyacosit has recently received a Masters of Science Degree from the University of California, Berkeley's School of Public Health, from the Environmental Health Sciences Division. Her specialization within the Environmental Health Sciences division is Health, Environment and Development, looking at the relationship between health and environment in developing countries. 


\title{
A Review of Particulate Matter and Health: Focus on Developing Countries
}

\author{
Lily Panyacosit
}

\section{Introduction}

The burden that has been placed on human health by particulate air pollution is a global one, one wrought with inequality. Most striking is the imbalance between the developed and developing countries in the burden of ill health attributable to particulate matter (PM) in our air. It is not uncommon for developing countries today to experience the same PM levels that characterized the devastating "London fog episodes" of the 1950s which resulted in thousands of cases of premature mortality and countless cases of exacerbated morbidity related health endpoints. The severity of the situation in developing countries warrants a closer look at and characterization of the key components that are integral to assessing the human health effects derived from exposure to particulate air pollution. This paper reviews the evidence for the relationship between particulate matter and health in developing countries through characterization of PM source/concentrations, people's exposure and behavioral patterns, potential human health endpoints, and health related costs.

Particles in the air are classified by aerodynamic diameter size and chemical composition. In terms of chemical composition, particulate matter is classified into two categories, primary and secondary particles. Primary particles are composed of particles that are emitted directly into the atmosphere from sources such as sea spray, windblown soil, road traffic, coal burning, and industry. Secondary particulates are the production of chemical transformation of $\mathrm{SO}_{2}, \mathrm{NO}_{\mathrm{x}}, \mathrm{HCl}$ and ammonium compounds under atmospheric conditions. The total airborne particulates in the air are referred to as Suspended Particulate Matter, and the term Total Suspended Particulates (TSP) implies that a gravimetric procedure was used to determine suspended particulate matter (SPM) concentrations. Much of the literature also makes reference to PM in terms such as PM10, PM2.5, coarse, fine, and ultrafine particles. PM10 and coarse particles, synonymous terms, both refer to PM with an aerodynamic diameter of $\leq 10 \mu \mathrm{m}$. PM2.5 and fine particles also both refer to PM with a diameter of $\leq 2.5 \mu \mathrm{m}$, while the ultrafine particles are those with a diameter of $<0.1 \mu \mathrm{m}$. The distinction between coarse and fine particles are made due to differences in sources, formation mechanisms, composition, 
atmospheric lifetimes, spatial distribution, indoor-outdoor ratios, temporal variability in addition to size, and health impacts (Wilson et al. 1997).

Table 1: Comparison of Fine Versus Coarse Mode Particles (Source: Spengler et al. 1996).

\begin{tabular}{|c|c|c|}
\hline & Fine Mode Particles & Coarse Mode Particles \\
\hline Composed of: & $\begin{array}{l}\text { Sulfate, } \mathrm{SO}_{4}^{2-} ; \mathrm{Nitrate} \mathrm{NO}_{3}^{-} \\
\text {Ammonium, } \mathrm{NH}_{4}^{+} ; \\
\text {Hydrogen ion, } \mathrm{H}^{+} ; \\
\text {Elemental carbon, } \mathrm{C} ; \\
\text { Organic Compounds; } \mathrm{PAH} ; \\
\text { Metals, } \mathrm{Pb}, \mathrm{Cd}, \mathrm{V}, \mathrm{Ni}, \mathrm{Cu}, \mathrm{Zn} ; \\
\text { Particle-bound water; } \\
\text { Biogenic organics. }\end{array}$ & $\begin{array}{l}\text { Resuspended dusts, soil dust, street } \\
\text { dust; } \\
\text { Coal and oil fly ash; } \\
\text { Metal oxides of } \mathrm{Si}, \mathrm{Al}, \mathrm{Mg}, \mathrm{Ti}, \mathrm{Fe} \text {. } \\
\mathrm{CaCO}_{3}, \mathrm{NaCl} \text {, sea salt; } \\
\text { Pollen, mold spores, plant parts. }\end{array}$ \\
\hline Sources: & $\begin{array}{l}\text { Combustion of coal, oil, gasoline; } \\
\text { Transformation products of } \mathrm{NO}_{\mathrm{x}} \text {, } \\
\mathrm{SO}_{2} \text {, and organics including } \\
\text { biogenic organics, e.g., terpenes; } \\
\text { High temperature processes; } \\
\text { Smelters, steel mills, etc. }\end{array}$ & $\begin{array}{l}\text { Resuspension of soil tracked onto } \\
\text { roads and streets; } \\
\text { Suspension from disturbed soils, } \\
\text { e.g., farming, mining; } \\
\text { Resuspension of industrial dusts; } \\
\text { Construction, coal and oil } \\
\text { combustion, ocean spray. }\end{array}$ \\
\hline Lifetimes: & Days to weeks & Minutes to hours \\
\hline $\begin{array}{l}\text { Travel } \\
\text { Distance: }\end{array}$ & 100 s to 1000 s of kilometers. & 1 to 10 s of kilometers. \\
\hline
\end{tabular}

Size, shape, reactivity, and particle density are all factors that determine the mechanisms of particle deposition. Deposition of particles occurs by a plethora of processes, categorized as primary and secondary. Primary mechanisms of deposition refer to movements dictated by size, shape and density of the airborne particles, and include settling, inertial impaction, and diffusion, also known as Brownian motion. Secondary mechanisms of particle deposition are more dependent upon the reactivity of the particles resulting in such mechanisms as interception and electrostatic attraction between charged particles and the charge on the to-be-impacted surface (Foster 1999). These factors inevitably influence where the particles will deposit within the human body as well. Generally speaking, the smaller the particle is, i.e., the smaller the diameter size, the more deeply it will deposit within the respiratory tract and at an increasing rate. In the nasal-breathing mode, the cilia and the mucus act as a very effective filter for most particles exceeding $1 \mu \mathrm{m}$ in diameter. During oral breathing, particle deposition within the respiratory tract depends not only on particle characteristics, but also human characteristics, i.e., is the person being active, or breathing deeply? The particles that are most relevant in terms of human health effects 
are those particles that are in general less than $10 \mu \mathrm{m}$ in diameter, which are often referred to as "inhalable particles". Those particles can penetrate anywhere within the respiratory tract beginning with the nasal passages to the alveoli, deep within the lungs according to diameter size (Spengler et al. 1996) (Table 2, Figure 2 and Figure 3).

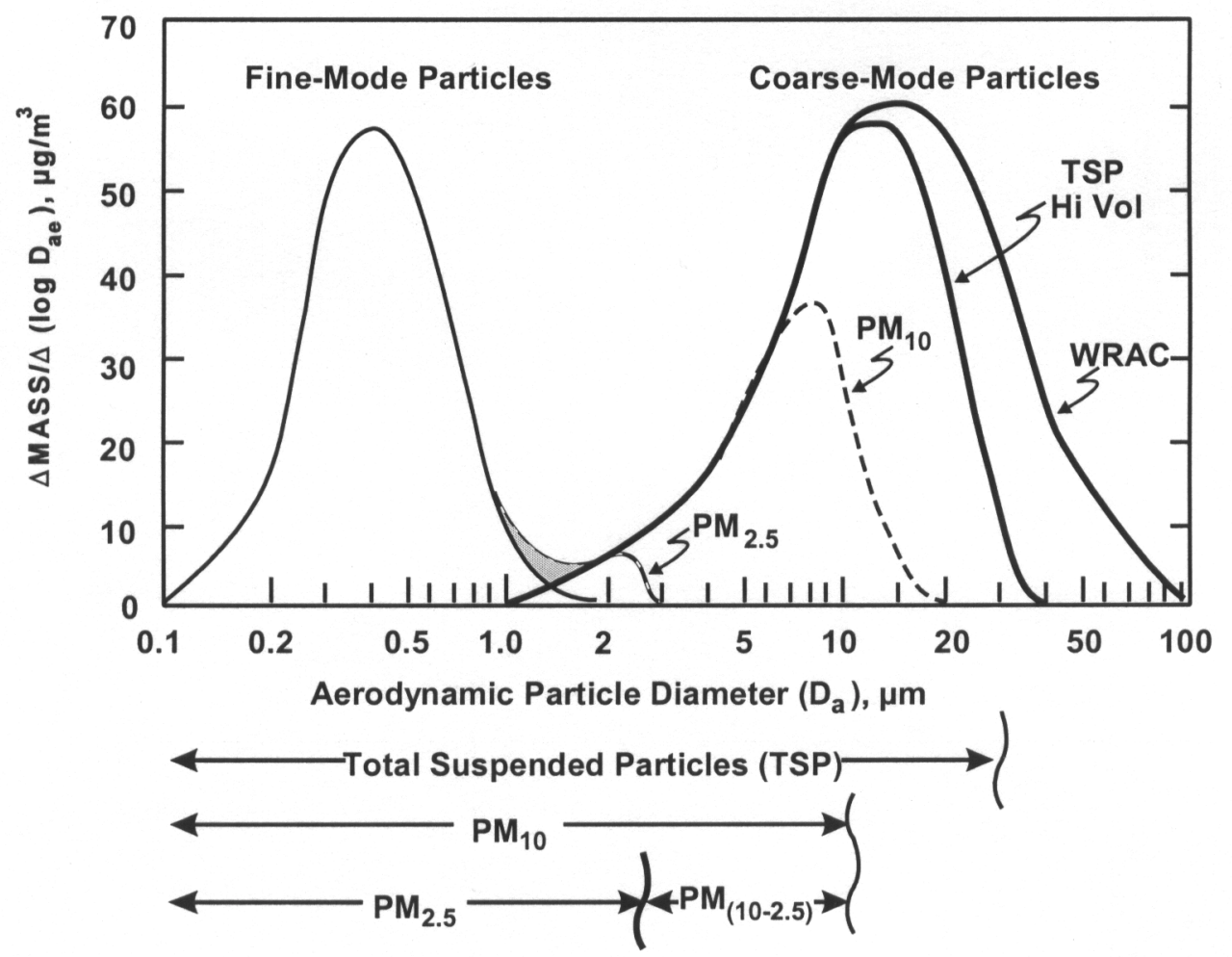

Figure 1: Size distribution of fine particles and fractions collected by size-selective samplers (US-EPA 1996).

Table 2: Respiratory Penetration vs. Particle Size (source: Spengler et al. 1996).

\begin{tabular}{|c||l|}
\hline Particle size (range) & \multicolumn{1}{|c|}{ Penetration of particles } \\
\hline \hline $11 \mu \mathrm{m}$ & and up particles do not penetrate \\
\hline $7-11 \mu \mathrm{m}$ & and up particles penetrate nasal passages \\
\hline $4.7-7 \mu \mathrm{m}$ & particles penetrate pharynx \\
\hline $3.3-4.7 \mu \mathrm{m}$ & particles penetrate trachea and primary bronchi \\
\hline $2.1-3.3 \mu \mathrm{m}$ & particles penetrate secondary bronchi \\
\hline $1.1-2.1 \mu \mathrm{m}$ & particles penetrate terminal bronchi \\
\hline $0.65-1.1 \mu \mathrm{m}$ & particles penetrate bronchioli \\
\hline $0.43-0.65 \mu \mathrm{m}$ & particles penetrate alveoli \\
\hline
\end{tabular}




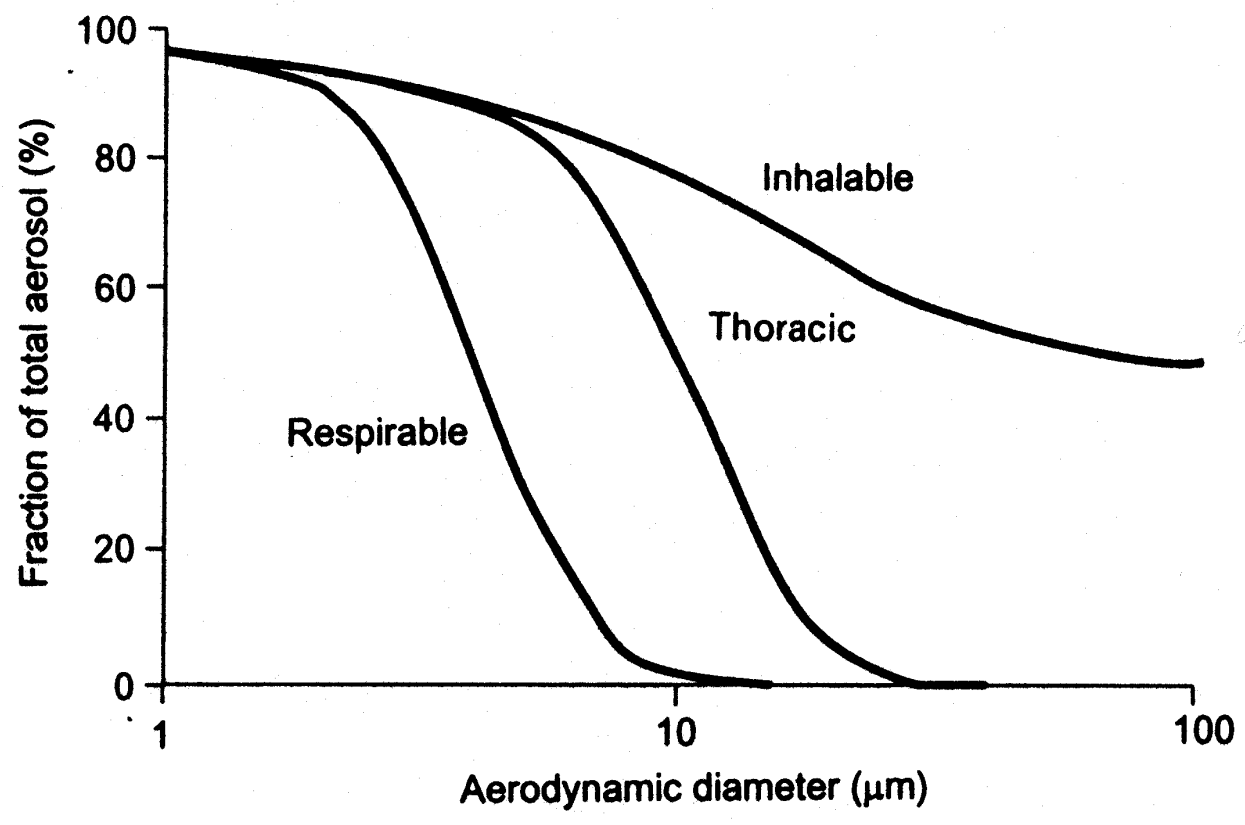

Figure 2: Typical Curves Defining Respirable, Thoracic and Inhalable Particle Fractions (source: The U.K. Department of the Environment 1993).

In addition to the particle characteristics listed above, there is also a "human" and "environmental" component that dictates the type and frequency of human health effects observed. The "human" component is dominated by the exposed person's physical characteristics, and breathing mode, rate and volume. The "environmental" component is influenced by local conditions, such as weather, seasons, topography, sources of particles, the concentrations being emitted, and microenvironments. To varying degrees, these three components determine the exposure effectiveness, i.e., the fraction of released material that actually enters someone's breathing zone, and the dose actually received, i.e., the concentration of PM that is actually breathed in, by the exposed person (Smith 1993).

International research efforts have been focussed on defining and characterizing the components, inhalable particles, human and environmental influences. These components differ significantly from region to region, and from population to population, therefore to do so for all developing countries is truly a daunting task. The extent to which these components have been characterized has been minimal at best, and concentrated in regions where data is available and easily accessible, such as the cities for which there is the Global Environmental Monitoring System (GEMS) data. This paper reviews a number of studies, both epidemiological and toxicological, that examine and evaluate the relationship between particulate matter and health. This paper attempts to give a comprehensive overview by synthesizing the pertinent information relating to source and concentration of PM, the exposure-response curves that have been fitted to PM exposure, the observed health effects, the plausibility of biological 
mechanisms, and health related costs of PM, and finally briefly considers the feasibility of extrapolating data derived from developed countries to estimate health effects for developing countries.

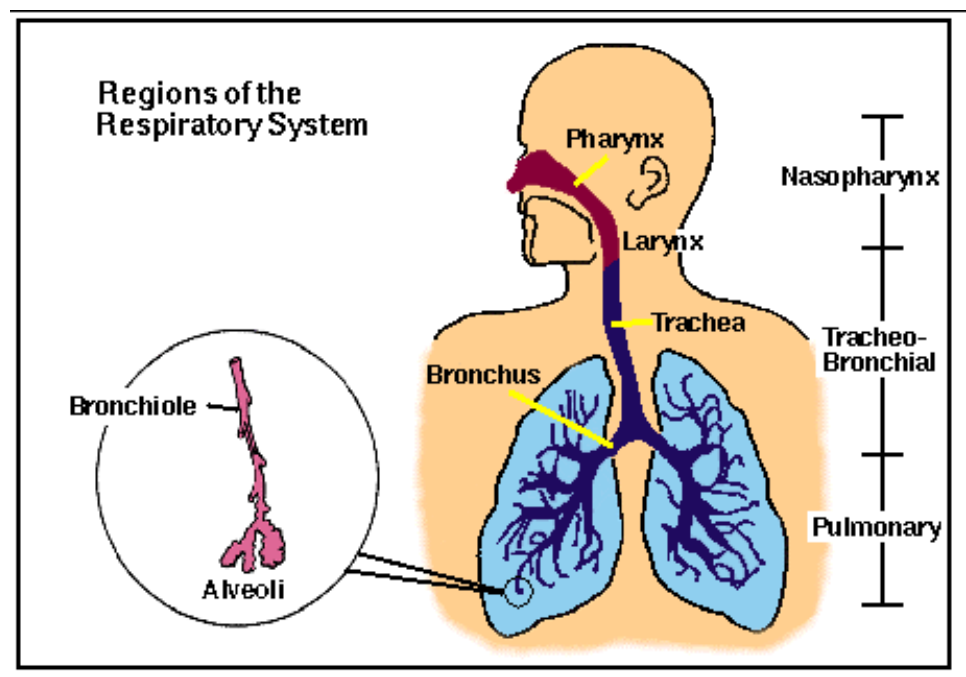

Figure 3: Relevant Regions of the Respiratory System from Exposure to Particulate Matter.

\section{Sources of Particulate Matter}

Concentrations of particulate matter vary widely across developing countries. There are significant differences in sources and concentrations of PM present between urban and rural areas, and between indoor and outdoor areas. Concentrations also depend on whether PM has a long or short residence time in the air. Long residence time translates into long-distance transport and transboundary air pollution problems, which could have serious repercussions for the areas surrounding the polluted area. Already it is a difficult task to attempt to assign the amount of human health effects observed to a single source. But adding transboundary air pollution to the equation makes it even more difficult to discern exactly how much of the human health effects may be attributable to local sources and/or regional sources.

\subsection{Urban versus Rural Emission Sources}

In addition to problems of local versus regional sources, urban and rural areas in developing countries also merit a closer examination as they exhibit unique characteristics with respect to PM sources and concentrations and each other. Rural areas contain approximately two thirds of the developing world population, although 
this is slowly changing with urbanization. Urbanization is a process that has characterized much of the developing world in the latter part of the twentieth century. The majority of the megacities in the world are located in the developing world. Most of those cities are ill equipped to absorb such a fast growing population. The lack of infrastructure has brought on severe problems such as waste management, lack of clean water and sanitation and high levels of air pollution (The Committee for the Analysis of PAHO Mission and Planning 1998).

Caught in a period of economic transition, urban centers of the developing world have a curious mix of rural air pollution problems of the developing world and urban air pollution problems of the developed world. A survey conducted by the WHO in 1994 looked at air pollution levels in 12 megacities, 10 of which were located in developing countries. Megacities located in developing countries have a wider range of air pollution sources compared to cities located in developed countries. The range of sources, however, is closely linked with key factors such as level of motorization, and the level, density, and type of industry present (WHO 1994). Sources of air pollution within megacities include motor traffic, power generation and industry, domestic coal and biomass fuel use, open burning of refuse, natural wind blown particles.

Motor traffic is the most important source of PM in cities with a high motor vehicle density, e.g., in Latin America. The majority of the cars in some developing countries are diesel powered, which generate on the order of ten times more respirable particles than gasoline engines per kilometer driven (Rallis 1988, Krupnick 1991). Cars found in developing countries also tend to be older and thus more polluting. Vehicles play a much less significant role in pollution where there is either a lower level of motorization, e.g., in Africa, or PM sources are dominated by domestic coal or biomass fuel combustion, e.g., in temperate regions such as China and parts of Eastern Europe.

In addition to the sources of air pollution within the developing countries, topography will also influence the fate of air pollution. The WHO has divided the megacities under examination into one of three categories:

- Cities not influenced by a body of water, under which fall cities such as Beijing, Cairo, Delhi, and Moscow;

- Cities influenced by a body of water with a relatively level topography, which include Bangkok, Bombay, Buenos Aires, Calcutta, Jakarta, Karachi, London, Manila, and Shanghai;

- And cities whose meteorology is influenced by surrounding mountains with a variable topography, which include Mexico City, Santiago, Rio de Janeiro, and São Paulo.

These topographical features as well as certain seasonal features can either exacerbate or lessen the problems related to the severity of air pollution. In cities located in regions with temperate and cold climates fuel consumption due to heating is higher than in areas with moderate and warm climates. Meteorological phenomena such as thermal inversions are more frequent. Thermal inversions reduce the dilution and dispersion capability of the atmosphere and trap air pollutants (including PM) close to the emission source (Terblanche 1993). Similar effects are seen in areas that are surrounded by 
mountains, where mountains act as a barrier and trap air pollution close to the city (WHO 1994).

Sources of PM in rural areas of developing countries can differ quite significantly from those that were observed in the megacities of the world. They are dominated by domestic sources, namely stoves used for cooking, and in the colder climates, for space heating as well. In 1988, about half of the world's households used unprocessed biofuels such as wood, dung, and crop residues for daily cooking purposes (Smith 1988). Most unprocessed biofuels and fuels such as coal are high emitters of particulate matter, and a multitude of other pollutants such as sulfur oxides, nitrogen oxides, hydrocarbons, and carbon monoxide (Smith 1988). Type of biofuel used, and thus emissions, varies from region to region.

In China, coal is burned in unvented stoves, whereas in most of South Asia, kerosene is used in inexpensive stoves giving off high levels of particulate emissions. Africa's fuel consumption drives the use of such biofuels as wood, which has led to problems of deforestation in some sub-Saharan African regions. Wood fulfills the fuel consumption needs of some $90 \%$ of the urban households in Africa for cooking, and is probably as high if not higher in rural areas (Krupnick 1991). In general, biofuels are used in developing countries because of their availability and affordability. The use of poor quality biofuels decreases with development, thus the least developed areas are most likely to experience the highest levels of air pollution (Smith 1993). Cookstove efficiencies, according to fuel, are $20 \%, 30 \%, 50 \%$, and $70 \%$ for wood, charcoal, kerosene, and Liquid Petroleum Gas (LPG) stoves respectively. Unfortunately fuel efficiency seems to be inversely correlated with the amount of health damaging pollutants it emits per joule of energy (Smith 1994). Biofuels such as wood, charcoal and kerosene emit known carcinogens such as 1,3 butadiene, benzene and benzo[A]pyrene. For these reasons, Smith observes that air pollution tends to be worse in rural indoor environments than urban outdoor environments (Smith 1988).

\subsection{Concentrations}

\subsubsection{PM Concentrations and Measurements}

$\mathrm{PM}$ in the air is a complex mixture of particles from primary sources (direct emissions to the atmosphere) and secondary sources (chemical transformation in the atmosphere). Particulate matter measured at different locations may differ considerably in sizes as well as in chemical and physical properties.

In developed countries, the difference between the mass concentration of TSP and PM10 and between PM10 and PM2.5 is usually larger in urban and industrial areas than in rural areas. This is due to the larger fraction of relatively small secondary particles in rural areas, originating mainly from long-range transport of air pollutants (Tarrasón and Tsyro 1998). Sedimentation and deposition of large particles takes place close to the emission sources. Thus, the proportion of PM2.5 relative to TSP and PM10 is usually higher in rural areas. Typical contributions of sulfate, nitrate and ammonium particulates to the total PM2.5 mass are about $40 \%$ in urban areas and 50\% in rural 
regions (e.g., Seinfelt and Pandis 1998). Elemental and organic carbon is the second significant component contributing to PM2.5 mass. However, in developing countries primary PM emissions from local sources such as stoves (heating and cooking) may influence ambient PM concentrations in urban and rural areas to a bigger extent than in developed countries (see Chapter 3.1).

Peters and colleagues (1997) looked at both size and mass concentrations of fine PM, i.e., PM2.5 in Erfurt, a city in Eastern Germany. Ambient air samples were taken during winter months in 1991 and 1992. Since Erfurt is located in a valley (Thüringer Wald), frequent inversions trap air in the city in winter. Peters and colleagues (1997) found that ultrafine particles accounted for $73 \%$ of the particles counted per $\mathrm{cm}^{3}$ air even though their total contribution to the mass concentration of all fine particles was approximately 1\%. And as size of the particles increased, their contribution to the total number concentration decreased, while their contribution to the overall mass concentration increased (Peters et al. 1997). The number concentration of particles is dominated by the ultrafine particles whereas the mass concentration of the particles is dominated more so by the slightly larger particles of diameters $0.1-0.5 \mu \mathrm{m}$.

Most monitoring stations in developed and developing countries are located in urban areas. Thus, information on ambient PM concentrations in rural areas is generally sparse. PM measurement results depend also on the sampler type used. A wide variety of particulate sampling instrumentation is available, e.g., impactor samplers, filterpack or denuder systems. The samplers usually collect selected parts of the SPM, e.g., containing teflon filters with a $2-\mu \mathrm{m}$ pore size collecting fine PM2.5 and coarse PM2.5 to PM10. Additionally, there are different techniques to analyze the samples, e.g., gravimetric methods to measure mass concentrations or X-ray analyses and ion chromatography to detect selected chemical elements. Few studies on comparing different sampling and analytical methods have been conducted so far, emphasizing that there is a need to introduce reference methods within monitoring programs (e.g., in Canada; Nejedlý et al. 1998).

\subsubsection{PM Concentrations in Developing Countries}

The particulate matter concentrations that have been observed in developing countries have traditionally been high, much higher than those seen in developed countries. The literature gives a wide array of measurements, making it difficult to directly compare the results. Measurements are given as outdoor ambient concentrations of PM, indoor concentrations of PM and personal exposures measurements. Most of the measurements are taken for the duration of the study period. Thus long-term PM measurements are not available. One of the only programs to actually measure longterm concentrations is the Global Environment Monitoring System (GEMS) air monitoring program established by the World Health Organization (WHO) in 1973. Many of the studies cited in this literature review use data from the GEMS airmonitoring program. GEMS is set up to monitor for pollutants such as sulfur dioxide 
$\left(\mathrm{SO}_{2}\right)$ and SPM, and measurements are made at two or three designated sites per city (Bennett et al. 1985).

Krzyzanowski and Schwela (1999) looked at trends of air pollution using WHO's Air Management Information System (AMIS), a part of the GEMS air monitoring program, as the main source of measurements. The 1990s data show both increasing and decreasing trends in a similar number of cities, with no systematic and/or significant change in TSP levels. Both Bangkok and Mexico City exhibited decreases in TSP levels, although Mexico City more consistently than Bangkok. Certain Chinese cities, on the other hand, have experienced increases in TSP levels, with the fastest rising levels occurring in Guangzhou, from less than $150 \mu \mathrm{g} / \mathrm{m}^{3}$ in $1990-1992$ to more than $300 \mu \mathrm{g} / \mathrm{m}^{3}$ in recent years. PM10 levels were also measured for some cities. The highest concentrations were found in Calcutta and New Delhi with levels exceeding 200 $\mu \mathrm{g} / \mathrm{m}^{3}$. The majority of the PM10 concentrations observed fell within the range of 50$100 \mu \mathrm{g} / \mathrm{m}^{3}$. Already high PM10 levels were observed to increase over the last decade in most towns, even while TSP levels were falling (Krzyzanowski and Schwela, 1999). Some Southern American cities experienced the reverse trend, and had falling PM10 levels. In Mexico City, however, the relative decrease in PM10 was greater than that of TSP.

A report entitled "Air Pollution in Megacities" was put out in 1994 by the WHO to compare air pollution problems in 20 megacities, the majority of which located in developing countries. Given that the WHO air pollution guidelines at this time for TSP were $100 \mu \mathrm{g} / \mathrm{m}^{3}$ for annual mean concentrations, $150-230 \mu \mathrm{g} / \mathrm{m}^{3}$ for 24-hour mean concentration, and $70 \mu \mathrm{g} / \mathrm{m}^{3}$ for PM10 24-hour average concentration, the WHO found that the majority of the megacities were out of compliance.

Of the 20 megacities that the WHO looked at in their Air Pollution in Megacities report, 17 of them had suspended particulate matter levels exceeding WHO guidelines by up to or more than a factor of two. SPM is a critical problem in megacities, but even more so in cities with simultaneously high concentrations of $\mathrm{SO}_{2}$. The annual average of levels of SPM across these cities range from $200-600 \mu \mathrm{g} / \mathrm{m}^{3}$. Peak concentrations can be as high as $1000 \mu \mathrm{g} / \mathrm{m}^{3}$ (WHO 1994).

TSP and PM10 concentrations have also been measured within several other studies addressing developing countries (summary in Tab. 3). $\mathrm{Xu}$ and colleagues report maximum TSP levels in Beijing for the year 1988 to be around $1003 \mu \mathrm{g} / \mathrm{m}^{3}$ (Xu et al. 1995). Other reports include maximums of approximately $1255 \mu \mathrm{g} / \mathrm{m}^{3}$ in Beijing (Xu et al. 1995). In the urban and industrial areas of São Paulo state, measurements of TSP were taken in the early $1990 \mathrm{~s}$, and gave readings up to $272.0 \mu \mathrm{g} / \mathrm{m}^{3}$ (Sato et al. 1995). Studies conducted in Mexico City looked at TSP levels for 1990 through 1992 and found maximum levels of $456 \mu \mathrm{g} / \mathrm{m}^{3}$, where measurements were recorded every sixth day as a 24-hour integrated measure (Borja-Aburto et al. 1997) PM10 levels were also measured giving average readings of $166.8 \mu \mathrm{g} / \mathrm{m}^{3}$ for 24 hours (Romieu et al. 1996). A study conducted in Lucknow, India had measurements of SPM, for 1993 to 1994, of $370.3 \mu \mathrm{g} / \mathrm{m}^{3}$ with a standard deviation of $80.0 \mu \mathrm{g} / \mathrm{m}^{3}$ (Awasthi et al. 1996a). Cropper and colleagues' measurements for TSP between the years 1991 and 1994 (Delhi) found a 24 hour average level of $378 \mu \mathrm{g} / \mathrm{m}^{3}$, and reached a maximum concentration of 1714 
$\mu \mathrm{g} / \mathrm{m}^{3}$. TSP levels in Delhi exceeded the WHO's 198724 hour standard on $97 \%$ of all days on which readings were taken (Cropper et al. 1997).

Table 3: Reported PM10 and TSP Levels in Developing Countries.

\begin{tabular}{|c|c|c|c|c|}
\hline \multirow[b]{2}{*}{ Reference } & \multirow[b]{2}{*}{ Location } & \multicolumn{3}{|c|}{ TSP concentrations $\left(\mu \mathrm{g} / \mathrm{m}^{3}\right)$} \\
\hline & & Minimum* & Mean* & Maximum* \\
\hline $\begin{array}{l}\text { Xu et al. } 1995 \mathrm{a} \\
\text { (yearly measurements) }\end{array}$ & Beijing, China & & 375 & 1003 \\
\hline $\begin{array}{l}\text { Xu et al. } 1995 \mathrm{c} \\
\text { (yearly measurements) }\end{array}$ & Beijing, China & & 388 & 1255 \\
\hline Sato et al. 1995 & Sao Paulo, Brazil & 66.9 & & 272 \\
\hline \multirow[t]{2}{*}{$\begin{array}{l}\text { Borja-Aburto et al. } \\
1997\end{array}$} & $\begin{array}{l}\text { Mexico City, } \\
\text { Mexico }\end{array}$ & 66 & & 456 \\
\hline & & \multicolumn{3}{|c|}{ PM10 Concentration $\left(\mu \mathrm{g} / \mathrm{m}^{3}\right)$} \\
\hline Awasthi et al. 1996a & Lucknow, India & & 370.3 & 450 \\
\hline Cropper et al. 1997 & Delhi, India & & 378 & 1714 \\
\hline
\end{tabular}

* Unless otherwise noted, measurements are 24 hour averages.

Although measurements of PM are taken as TSP and to a lesser extent PM10, the more health relevant particles are PM10 or smaller. Thus available data on PM10 and TSP has allowed ratios of PM10/TSP to be calculated. In developing countries where this information is accessible, the range is approximately from 0.4-0.8 (Krzyzanowski and Schwela 1999). A PM10/TSP ratio of 0.5 was found for Mexico City (Borja-Aburto et al. 1997). In a Bangkok study, ratios of PM2.5 to PM10 were looked at for indoor and outdoor environments and found to be ranging from 0.45 to 0.88 indoors, and 0.48 to 0.86 outdoors (Chestnut et al. 1998).

Since most of the measurement data in developing countries is only for TSP and PM10, Wilson and Suh (1997) used available data from Philadelphia, PA, to more closely examine the relationship between the health relevant PM fractions, i.e., PM10, PM2.5. Both the mass and the number of particles in the PM10 category are comprised of PM2.5 $(<2.5 \mu \mathrm{m})$ and PM10-2.5 $\mu \mathrm{m}$, but the question is to what degree. PM2.5 dominates both the PM10 mass and number concentrations, and as such actually is the primary cause of the day-to-day variability in PM10. PM2.5 contributes approximately 2.75 times more variability to PM10 than PM10-2.5 (Wilson and Suh 1997). In addition, PM10 and PM2.5 levels exhibited a high degree of correlation whereas the lowest level of correlation existed between PM10-2.5 and PM2.5. 
The conclusion reached seems to be that in cities with fine particulates exceeding levels of coarse PM, the variation in PM10 arises mostly from the fine particulates (Wilson and Suh 1997). If this conclusion can be generalized for all areas with higher levels of fine PM than coarse particulates, then it may be reasonable to use PM10 as a proxy for exposure to PM2.5. This finding seems to be fairly important as more and more research finds that human health risks are increasingly associated with the finer fraction of PM.

\section{Exposure-Response}

The vast majority of epidemiological studies that have looked at associations between mortality and morbidity endpoints and air pollution use outdoor air pollution measurements. And in this manner, particulate matter concentrations in the ambient environment have been used to represent human exposure levels as happens to be the case for both developed and developing countries. The human exposure levels linked to observed human health effects have traditionally been characterized by what we term "dose-response curves", but are actually "exposure-response curves". Employment of the term dose-response implicitly implies a false degree of precision in the monitoring of human exposure levels,i.e., that the dose received by exposed people is actually measured instead of being represented by proxy measurements. This paper will use the term exposure-response in the place of dose-response where appropriate. A true doseresponse relationship will be specified as such by defining that dose has actually been measured.

\subsection{Exposure: Indoor vs. Outdoor Air Pollution}

\subsubsection{Indoor and Outdoor PM Concentrations}

The degree of misrepresentation in exposure levels is contingent upon the relationship between indoor and outdoor air. A study conducted in Bangkok looked at the relationship between indoor and outdoor particulate matter concentrations (Chestnut et al 1998). Indoor PM levels were as high if not higher than outdoor levels when there was no air conditioning and some indoor sources present. With no notable indoor sources, and maybe some air conditioning, indoor PM concentrations ranged between $50 \%$ to $100 \%$ of outdoor concentrations. A Dutch study gave similar findings (Janssen et al. 1998). A good correlation existed between indoor and outdoor levels, but it decreased with increasing indoor sources, such as environmental tobacco smoke (ETS). These two studies found that in general, outdoor concentrations tended to exceed indoor concentration, whereas a Korean study found indoor air concentrations to be consistently higher than outdoor, an observation that was magnified during wintertime possibly due to heating (Baek 1997). All three studies cited the difference between indoor and outdoor concentrations as attributable in part to human indoor activities, duration of human occupancy, ventilation, type of stove used for cooking and heating, and tobacco smoke (Baek 1997). 
Emissions from cooking and heating contribute heavily to indoor air pollution. Coal and biomass fuels, e.g., wood, stubble, dung, and grass are used in about half of the world's households for these purposes. Coal is used for about $78 \%$ of total primary energy production in China (China Statistical Publishing House 1998). Emissions from coal combustion alone have been estimated at 18 million tons per year ( $\mathrm{Xu} \mathrm{1998).}$ Residential energy consumption accounts for $15 \%$ of total energy use in China, and coal is the main energy supplier for cooking and heating purposes contributing about $75 \%$ 95\% in 1991 (Peng et al. 1998).

In Beijing, China's economically developed capital, about $90 \%$ of all households use gas for cooking. In contrast in Nanning, a city located in the Guangxi-Zhuangzu province, $\sim 84 \%$ of all households use coal for this activity (Daxiong et al. 1994). Indoor PM10 concentrations in households using coal for cooking can be two to three times higher than the proposed air quality standards for industrial districts and traffic centers established by the National Environmental Agency (NEPA) in Beijing (Wu et al. 1987). In Nanning, e.g., PM10 concentrations are even seven times higher (Daxiong et al. 1994).

\subsubsection{Indoor Exposure}

In most of the developing world, fuels are used indoor are burned in open fires or inefficient stoves, with no or low smokestacks, and inefficient dust collection in poorly ventilated kitchens. Coal that is burned is primarily a low efficiency coal that has undergone no desulfurization process. With respect to coal, $90 \%$ or more of the particle mass from coal smoke is in an inhalable form ( $\mathrm{Xu}$ 1998). Predictably there are increased levels of respiratory disease and respiratory related mortality.

In comparing indoor and outdoor concentrations and their relative contributions and influences in human exposure patterns, one should also take into consideration where people spend their time. People spend the majority of their time indoors. The developing countries are comprised of approximately three-quarters of the world's population. People in developing countries spend about $70 \%$ of their time indoor, and $30 \%$ outdoors. People in developed countries spend also a majority of their time indoors, but this proportion is greater, approximately 87\% (Smith 1993). Using ambient outdoor concentrations of particulate matter to represent exposure levels may actually lead to misinterpretation. .

For areas with no significant indoor air sources, outdoor ambient concentrations may be a good indicator of changes in a person's exposure from day to day (Chestnut et al 1998). Thus, from measuring ambient concentrations, high concentrations would signify that a person's exposure would be high as well, the same concept could be applied to low concentrations and changes in concentrations. There is additional evidence, however, that point to the fact that indoor air pollution stemming from household coal and biomass use can significantly contribute to urban ambient pollution (Smith correspondence 1999). This would signify that day to day fluctuations in indoor particulate matter may correlate fairly well with measurements of outdoor fluctuations. 
Given that this assumption holds, it would explain why findings across epidemiological studies, especially in developed countries, remain so consistent. Total exposure to PM, which occurs mainly indoors, is reasonably well represented by variation in outdoor concentrations, i.e. high/low concentrations, or changes from high to low and vice versa represent more or less high/low changes in exposure, and more so with fine PM (Smith, personal communication). On the other hand, absolute PM exposure, i.e. personal exposure to particulate matter, is more or less misrepresented by ambient monitoring.

Janssen and colleagues (1998) found in the Netherlands a greater discrepancy between personal exposure and indoor/outdoor concentrations than between indoor and outdoor concentrations. Personal exposure was found to be hugely underestimated, although the direction and the degree of misrepresentation clearly depends on other factors such as indoor sources, housing type and condition, geographic location etc. (Janssen et al. 1998, Smith personal communication 1999).

A generalization could be made then that fairly dependent exposure response curves can be derived from ambient monitoring. The traditional method of estimating health effects, however, are derived from DOSE response curves, where a person's absolute exposure to the contaminant, i.e. particulate matter, is measured. Therefore if we were to attempt to more accurately assess the health impacts from exposure to PM for developing countries a more rigorous approach where real exposure assessment information, e.g., personal and/or indoor monitoring, or more studies quantifying the affects with respect to ambient monitoring, needs to be taken. Ultimately though, to estimate real impacts, i.e., absolute risks from a dose response curve, exposure assessment information is imperative.

\subsection{Exposure-Response Curves}

The WHO established air pollution health guidelines in 1987 for TSP and PM10, which have been stated earlier in this paper, are $100 \mu \mathrm{g} / \mathrm{m}^{3}$ for annual mean concentrations, $150-230 \mu \mathrm{g} / \mathrm{m}^{3}$ for 24-hour mean concentration, and $70 \mu \mathrm{g} / \mathrm{m}^{3}$ for PM10 24-hour average concentration (WHO 1994). USEPA guidelines for PM10 give $50 \mu \mathrm{g} / \mathrm{m}^{3}$ for an annual average and $150 \mathrm{~g} / \mathrm{m}^{3}$ for daily average (USEPA 1996). Since then, however, new evidence has come to light that those published guidelines are not low enough to safeguard against adverse health effects. In fact, there may be no concentration that is low enough to safeguard against deleterious health effects as no threshold has ever been established through animal studies or through epidemiological studies. Mortality and morbidity endpoints have been observed at levels even below the stated air quality guidelines put forth by the USEPA (Cotton 1993). This would imply that health effects associated with particulate air pollution are ever present during a PM episode, and increase with increasing concentrations of PM, becoming discernible at higher levels of PM. A preliminary consensus among many researchers is that at low concentrations, the relationship between PM and health effects is of a linear nature, whereas at higher PM10 levels, approximately above $200 \mu \mathrm{g} / \mathrm{m}^{3}$, the relationship becomes more curvilinear with the slope becoming shallower at higher ambient concentrations (Romieu 1999, Health Council of the Netherlands 1995). In line with these observations, the WHO has set no guideline for PM, but rather has developed exposureresponse curves to guide decision and policy makers. The curves show the relationship 
between the percent change of some health endpoints and the PM concentrations. The percent change is related to the risk for health effects to occur (Figures 4-6).

Percentage increase in daily mortality assigned to PM-10, PM-2.5 and sulfates

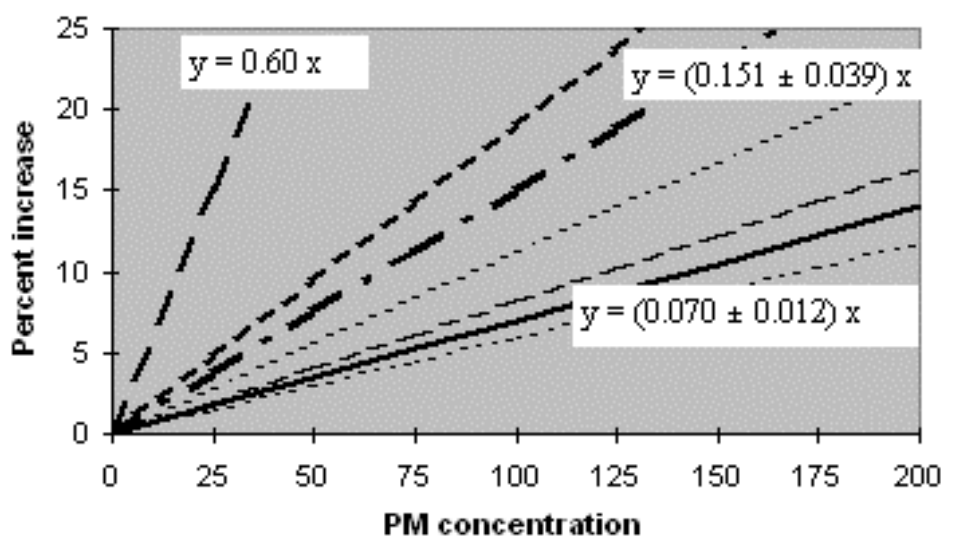

- Mean (PM-10)

- - - - Upper confidence lirnit

....... Lower confidence limit

- - Mean (PM-2.5)

- - Mean (sulfate)

Figure 4: Percentage increase in daily mortality assigned to PM10, PM2.5 and sulfates.

Percent change in health endpoints with PM-10

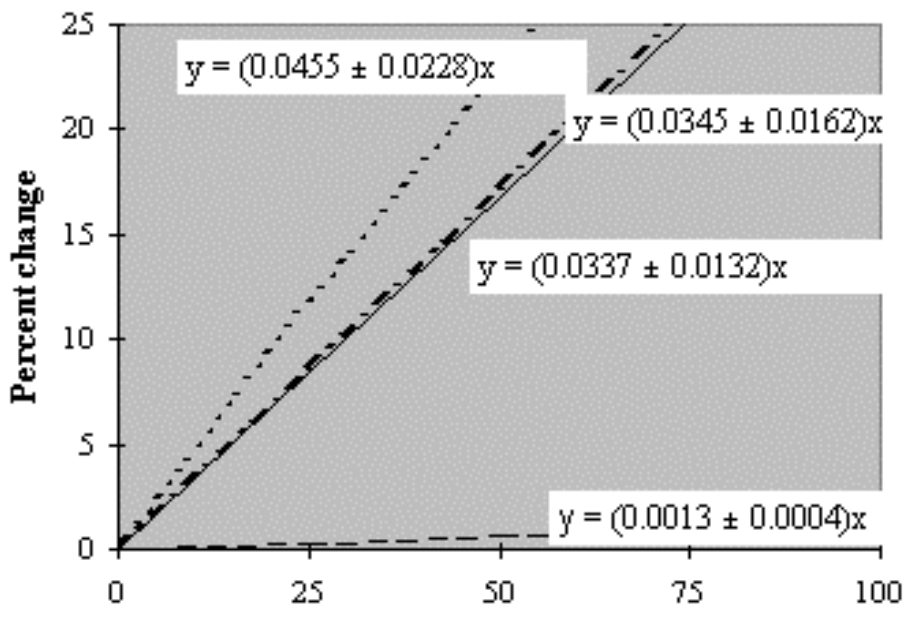

Bronchodilator use

- - - - Symptom exacerbation

...... Cough

- - - - Peak expiratory flow

PM-10 concentration [ug m-3]

Figure 5: Percent change in health endpoints with PM10. 

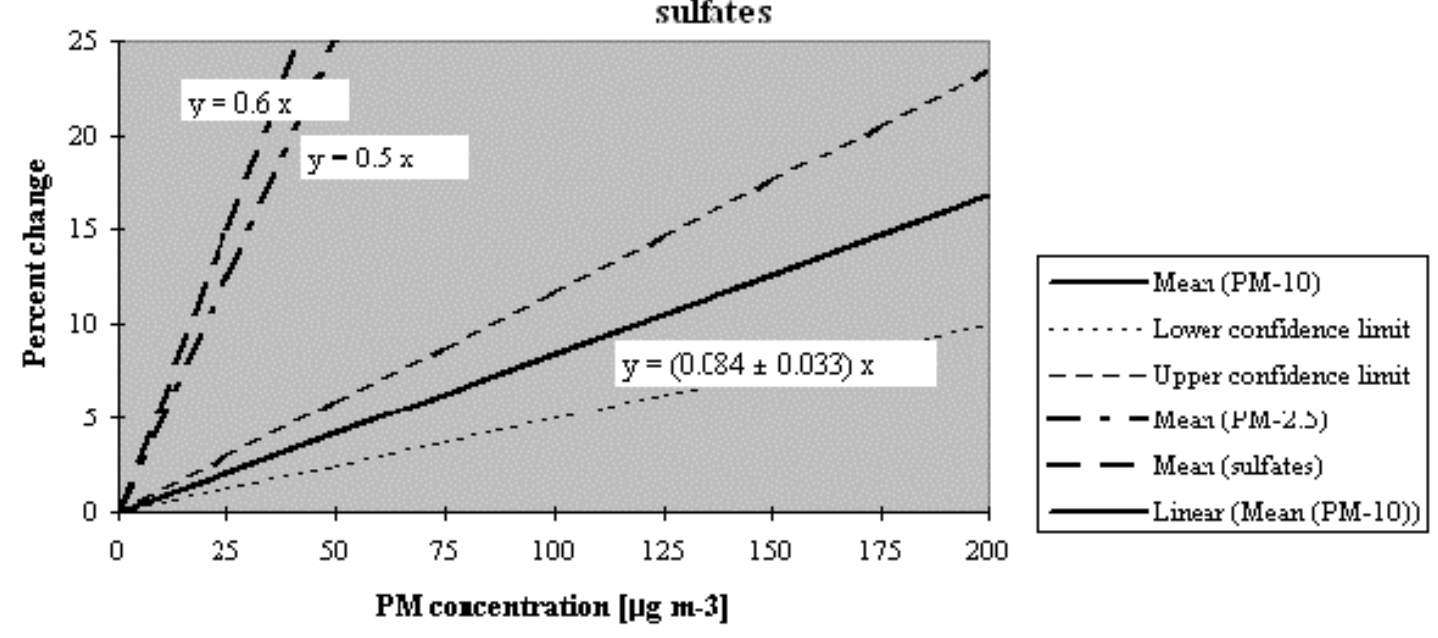

Figure 6: Percent change in hospital admissions assigned to PM10, PM2.5 and sulfates.

(Source: WHO air pollution guidelines; http://www.who.org/peh/air/airguides2.htm).

The WHO provides stipulations with these exposure-response curves. The stipulations are that "the graphs should not be used for concentrations below 20 or $10 \mu \mathrm{g} / \mathrm{m}^{3}$ respectively, or above 200 or $100 \mu \mathrm{g} / \mathrm{m}^{3}$, respectively. This is due to the fact that mean 24 hours concentrations below or above the quoted values could not be used for the risk assessment, and the curves presented in figures 1 to 3 would present invalidated extrapolations beyond the range of observed results" (http://www.who.org/peh/air/airguides2.htm).

The uncertainties associated with developing a exposure-response curve for PM and health effects based on the available data has also led to some speculation on why the dose response curve takes on a first linear and then non-linear form (at PM10 > 200 $\mu \mathrm{g} / \mathrm{m}^{3}$ ). The first hypothesis is that the shape of the curve may be attributable to a phenomenon known as harvesting, where the early deaths from air pollution are mainly individuals who are susceptible to the effects of air pollution. This subsequently reduces the amount of people that are susceptible to premature mortality from exposure to air pollution. Therefore as PM levels increase in the beginning, the number of deaths also increase in the beginning, but as the pool of people who are at risk for premature mortality decreases, so does the number of people dying even as air pollution continues to increase. Another hypothesis is that PM may actually be unwittingly used as a proxy for another pollutant that exhibits a non-linear relationship with PM in air pollution (Xu et al. 1994, Schwartz and Marcus 1990). 


\section{Health Effects}

Primarily, epidemiological studies are used to establish linkages between exposure to, in this case, particulate matter/air pollution and adverse health effects. But they provide little if any information regarding biological mechanisms of air pollution. Associations between adverse health effects and exposure to PM are enhanced by the replicability of the studies. Biological plausibility is reinforced by the observation of a coherent cascade of cardiopulmonary effects as well as the fact that non-cardiopulmonary effects are not typically associated with particulate matter pollution (Pope and Dockery 1999). Once an association and biological plausibility has been established, animal toxicology studies and/or human clinical trial studies are usually undertaken to define that biological mechanism. Within these studies it is especially difficult to accurately reproducing the relevant "particulate matter" mixture. PM is a complicated blend of chemicals that is dependent upon the primary source from which it originates, but also upon meteorological factors which could influence to what extent certain compounds will undergo secondary chemical transformations.

Epidemiological studies are categorized as either acute or chronic studies. Acute epidemiological studies typically use short-term changes in air pollution over time as the source of exposure variability, and relate those changes to changes in certain health endpoints related to particulate pollution. Chronic studies use longer-term pollution data, usually on the order of one year or more and tend to be cross-sectional by nature. Numerous studies have been done that have looked at and established quite firmly a relationship between certain health endpoints, such as premature mortality, and particulate pollution. The problem lies in the ability to compare results of these studies (in detail). With the number of studies being significantly less in developing compared to developed countries, the difference in the health endpoints examined, the measurement of PM, be it TSP, PM10 or PM2.5, and type of study either acute or chronic study, it is even more difficult to directly compare results.

\subsection{Acute Health Effects}

\subsubsection{Mortality}

The majority of the studies that have looked at health effects have been acute exposure studies (Table 4; Annex 1). These studies can be separated out into two groups of studies, studies looking at premature mortality, both general and disease-specific mortality, associated with exposure to particulate pollution, and studies looking at morbidity endpoints associated with the same exposure. The most common mortality endpoints looked at are: 
- total mortality,

- respiratory mortality,

- cardiovascular mortality,

- mortality from Chronic Obstructive Pulmonary Disease (COPD),

- Pulmonary Heart Disease (PHD).

Other mortality endpoints that are not as commonly used, but have been looked at are children's respiratory mortality, and intrauterine mortality. The studies examined in this report show a consistent positive correlation between exposure to particulate pollution and mortality. Of the studies reviewed, all show a significant association between PM concentration and mortality stemming from cardiovascular disease. Respiratory related mortality and total mortality was significantly related to PM levels in all studies but one. COPD related mortality was also significantly related to PM as opposed to Pulmonary Heart Disease (PHD) which was not. In developed countries, associations between PM and mortality ranged from $0.5 \%$ to $1.6 \%$ for each $10 \mu \mathrm{g} / \mathrm{m}^{3}$ increase in PM10, with an average increase of 1.0 percent (Ostro 1996). All mean TSP levels reported in these studies are relatively elevated. On the other hand, neither children's respiratory related mortality nor intrauterine mortality were found to be significantly associated with PM alone (Pareira et al. 1998, Saldiva et al. 1994). In spite of the fact that no relationship was noted between children's respiratory related mortality and PM, the results of Saldiva and colleagues (1994) point to the possibility of NOx increasing the susceptibility to respiratory infection and thus respiratory related mortality in the exposed population. Although intrauterine mortality was not significantly correlated with PM measurements alone, the authors found a significant association when looking at all the pollutants together (PM10, $\mathrm{NO}_{2}, \mathrm{SO}_{2}$ and $\mathrm{CO}$ ).

\subsubsection{Morbidity}

The significant association between acute mortality and particulate pollution provoked further interest in other possible health effects caused by air pollution. Studies in China, looking at morbidity related health endpoints found associations between high levels of particulate pollution and increased daily hospital admissions, non-surgery visits, where the association increased 1.5 to 2.0 fold for specific departmental visits, e.g. pediatric and internal medicine visits ( $\underline{\mathrm{Xu}}$ et al 1995c). The association between daily hospital admissions, hospital admissions from respiratory and cardiovascular symptoms, and PM was confirmed by a Bangkok study (Chestnut et al. 1998). Birth outcomes such as low birth weight and preterm delivery were also found to be significantly associated with high PM values. As has already been stated above, respiratory related symptoms were significantly correlated with PM pollution, measured by forced vital capacity (FVC) and forced expiratory volume (FEV), which decreased with increasing pollution levels. Other measures used to define respiratory related symptoms included presence of cough, phlegm, lower respiratory disease, bronchiolitis, respiratory symptoms complex, and exacerbation of asthma. Studies conducted in Santiago, Chile; Lucknow, India; Mexico City, Mexico; and Bangkok, Thailand confirmed one or more of these findings (Table 5; Annex 2). 


\subsection{Long-Term Health Effects}

\subsubsection{Chronic Studies}

Repeated exposure to particulate matter, with its obvious dire effects on acute mortality, is postulated to have longer-term health effects as well. There have been relatively few studies conducted that measure the health effects from chronic exposure to PM, and none that have been conducted in developing countries. Overall, the studies found a robust association between mortality and particulate matter, as well as higher levels of mortality in cities with higher average levels of particulate matter (Dockery et al. 1993; Popeet al. et al. 1995; Lipfert 1994). Dockery and colleagues reported an adjusted mortality rate ratio of 1.26 for the most polluted city compared to the least polluted city. Pope and Dockery reported that a $10 \mu \mathrm{g} / \mathrm{m}^{3}$ change in long-term exposure to PM10 is associated with a 4.2 percent change in annual all-cause mortality. What is most striking regarding the findings of these studies is the fact that they derive much higher risk estimates than do the daily time series studies, which might occur due to their inclusion of both acute and chronic effects. In addition chronic exposure studies are in general much more subject to confounding factors, such as socioeconomic status, smoking and others that may be more difficult to identify.

\subsubsection{Cancer}

In developing countries, the primary chronic health endpoints that researchers have hypothesized to be associated with PM, primarily through coal combustion, are cancer, primarily lung cancer (Table 6; Annex 3). The incidence of lung cancer in some cities of China, where there is heavy use of coal for cooking and heating, is almost as high or is as high in women as in men. This is rather a remarkable figure considering the fact that prevalence of smoking in men, at the time of the study, was about $40 \%$ and less than $0.1 \%$ in women (Mumford et al. 1987). Therefore the similarity in lung cancer prevalence was hypothesized to be due to presence of a cookstove and type of coal used in the cookstove. A study conducted in Fuzhou, China looked at possible risk factors associated with lung cancer, and using presence of a cookstove as a proxy for indoor air pollution. They found indoor air pollution to be a significant risk factor for lung cancer (Luo et al. 1996). In terms of the type of coal used, they found that mortality from lung cancer was higher in households or regions that used primarily smoky coal as opposed to smokeless coal (Mumford et al. 1987). In addition to lung cancer, use of biomass cooking fuels has been established to be a possible risk factor for nasopharyngeal cancer (Zhang and Smith 1996, Smith 1993).

Emissions have been found to contain carcinogenic compounds. Smith examined certain fuel/cookstove combinations in Manila and found some sixty hydrocarbons to be emitted from those stoves. A further study by Zhang and Smith (1996) examined emissions concentrations of specific known carcinogens, namely benzene, 1,3butadiene, styrene, and xylene. Because cancer risks are based on cancer potencies, the compounds with the highest cancer potencies will tend to dominate. In this case, cancer risks from xylene and styrene were negligible when compared to those of benzene and 1,3 butadiene. The cancer risks, which also depends on amount of emissions and type 
of fuel/cookstove combination used, were highest for 1,3 butadiene and then benzene, for wood, charcoal and then kerosene/wick stoves (Zhang and Smith 1996).

\subsection{Indoor Air Pollution Related Health Effects}

In addition to lung cancer, there is evidence to varying degrees supporting the associative relationship between indoor air pollution and a number of other debilitating health effects (Table 7; Annex 4). Women and children suffer the most serious health damages, as they are the most exposed population, with women being the cooks as well as the primary caretakers of the children in the household. Women and children living in coal consuming families have been demonstrated to suffer from increased prevalence of respiratory symptoms and disease than their gas consuming counterparts (Qin et al. 1991, Peng et al. 1998). A Gambian study found that girls under the age of five, who were carried on their mother's backs during cooking (in smoky cooking huts) increased their risk of developing Acute Respiratory Infection (ARI) up to six times. This was significantly higher than if their parents smoked (Schwela 1997). The strongest evidence or most abundant evidence available supports the relationship between indoor air pollution and health endpoints such as acute respiratory infections, chronic obstructive pulmonary disease, and lung cancer in women (Smith 1999). To a lesser degree, there is also evidence to support possible associations between tuberculosis, blindness and perinatal effects (Smith 1999).

\section{Biological Plausibility}

The evidence seems to be irrefutable, but is there a plausible biological mechanism that can support the myriad of findings? Particulate matter pollution seems to be related to all kinds of adverse health effects from before birth to death. A number of hypotheses have been posed as to how the toxicity of particulate matter may operate within the human body.

\subsection{Chemical Composition of Particulate Matter}

The first hypothesis relates to the acidity of particulate matter, specifically the acidity of fine particulate matter which are small enough to be able to deposit in the distal lung airway and airspaces. Acidic particles are thought to increase the acidity of mucus. Mucus acidity is positively correlated with mucus viscosity, thus with increased mucus acidity, one also has increased mucus viscosity. This will in turn increase airway resistance and thus decrease mucociliary clearance. Mucociliary clearance is an important respiratory defense mechanism against inhaled particles, bacteria and viruses. At a $\mathrm{pH}$ as low as 4.9, ciliary motion stops and epithelial cells begin to die. Studies in donkeys and rabbits showed that chronic exposure to sulfuric acid leads to irreversible impairment of mucociliary transport (Spengler et al. 1990). Airway resistance studies in guinea pigs and bronchial clearance studies in donkeys demonstrated that sulfuric acid was more of an irritant than sulfur dioxide (Amdur 1996). 
The populations that are most susceptible include those with pre-existing cardiopulmonary conditions and respiratory ailments such as asthma. Studies showed that asthmatics responded with an increase in airway resistance to concentrations of sulfur dioxide much lower than those needed to produce a response in normal subjects (Amdur 1996).

Heavy smokers tended to have a seriously impaired clearance function of particles in the bronchial region. Repeated exposure to sorbed sulfuric acid produced changes that were dose-related, progressive and related to cumulative dose. These exposures made the lung more sensitive to re-exposure to sorbed sulfuric acid and also to ozone exposure (Amdur 1996).

\subsection{Size of Particulate Matter}

Toxicity of PM may also be related to the size of the particles. In a study done on the rat, which is a species sensitive to ozone but quite insensitive to sulfuric acid, looking at the joint action of both pollutants found that sulfuric acid in general potentiates the rat's response to ozone. Morphological studies showed that the potentiation of the rat's response to ozone was attributable more so to the ultrafine sulfuric acid as opposed to fine sulfuric acid particles (Amdur 1996). A hypothesis proposed by Seaton and colleagues (1995) is that the ultrafine particles are inhaled and deposited in the lung acinus and the alveolus. The toxicity of the ultrafine particles is proposed to be dominated by the acidity of the particles and thus provokes alveolar inflammation which causes both changes in blood coagulability and release of mediators that can bring about incidences of acute respiratory illness in susceptible individuals. Again it has been proposed that the most susceptible populations consist of those with pre-existing cardiovascular disease (Seaton et al. 1995).

Studies have looked at the possibility of size being the primary factor in the toxicity of particulate matter. Studies found similar results looking at different compounds, namely titanium dioxide and carbon particles (Ferin et al. 1992, Li et al. 1996). Both studies suggest that ultrafine particles have toxicity that originates from their small size rather than their chemical composition. Possible mechanisms proposed by the authors include particle surface area, particle number, particle surface chemistry, oxidative stress and interstitialization of particles. The overload theory states that macrophage ability to move and carry their particle burden to the start of the mucociliary escalator for removal from the lungs is diminished at a certain concentration of particles. Essentially the macrophages' clearance ability is inhibited when the volume of particles inside the macrophages reaches approximately $60 \%$. Although in terms of ultrafine particles, volume of particles inside the macrophages may not be as important a factor as surface area. Ultrafine particles represent the biggest surface area per unit mass. In the study looking at the two particles sizes of titanium dioxide, the retention time of a radioactive marker particle in the lungs of rats exposed to ultrafine particles was increased about eight-fold compared to controls and macrophage load was only at about $2.6 \%$ volume. Conversely, for the fine particles, with a macrophage load volume of $9 \%$, retention time was only doubled (Ferin et al. 1992, MacNee et al. 1999). 
The third hypothesis states that the sub-micron sized acid particles may penetrate to the lower airways where the particles can irritate the ciliated epithelium that is not covered by a continuous mucus layer. It is conceivable that this may contribute to incidence of chronic bronchitis (Spengler et al. 1990). Another hypothesis is that respiratory responses to acid exposure are associated with available hydrogen ions $\left(\mathrm{H}^{+}\right)$rather than sulfate, sulfite, nitrate, and/or nitrite ions. The region in the respiratory tract on which the hydrogen ions are deposited depends on the chemical reactivity in the airways and the acid particle size (Spengler et al. 1990).

\subsection{Non-Respiratory Related Health Endpoints}

Most of these hypotheses contend with respiratory related health endpoints. A couple of the studies did look at health endpoints other than acute mortality and respiratory related ailments, such as low birth weight and preterm birth. An ecological study conducted in the US found an association between Sudden Infant Death Syndrome and air pollution (Woodruff et al. 1997). Biological mechanisms are as of yet still unclear, but hypotheses have been made. One hypothesis focuses on maternal exposure, where conditions such as maternal infection, intrauterine infection and systemic infections, conditions which may be provoked by exposure to air pollution, are thought to play a role in preterm births (Xu et al. 1995a). Other studies found toxic environmental substances present in umbilical cord blood so a possible hypothesis may be that these injurious birth related outcomes may be linked to the presence of those toxic environmental substances (Pareira et al. 1998). Atmospheric nitrogen oxides may also increase methemoglobin levels, which in turn may interfere with the oxygen-carrying capacity of hemoglobin in children (Pareira et al. 1998). Another hypothesis relating to a decrease in oxygenation, which may possibly lead to fetal death, is the presence of Carbon Monoxide ( $\mathrm{CO}$ ) hemoglobin $(\mathrm{COHb})$. $\mathrm{COHb}$ is known to have a dose dependent relationship with $\mathrm{CO}$, therefore air pollution could influence occurrence of fetal death (Pareira et al. 1998). Increasingly, however, there is evidence that early life experience, and potentially even fetal experiences, may increase or alter one's risk to disease in later life (McMichael et al. 1999). Low birth weight has been established as a risk factor for acute respiratory infections (Azizi et al. 1995), and a study in Mexico city puts forth the hypothesis that Mexican children who are chronically exposed to fine particles and ozone may experience lung damage (Romieu et al. 1999). According to McMichael et al. (1999) evidence from China indicates that chronic exposure to air pollution can impair lung function in non-smoking adults.

\section{Costs of Air Pollution}

While we have systematically gone through the health effects associated with air pollution in developing countries, no mention has yet been given to how they compare with those in the developed countries. Briefly, injurious health effects such as COPD and ARI occur at much higher rates in developing countries than in developed countries (Krupnick 1991, Pearce 1996). It would follow then that the costs incurred by air pollution are much higher than those in developed countries. 


\subsection{Exposure Response Functions}

Pearce (1996) calculated the health-related costs of particulate pollution for China, Cairo and Jakarta, and the benefits of a certain percentage reduction in PM levels for Mexico City, Bangkok and Santiago. Consensus exposure-response functions were used, thus damage costs were mainly determined by the size of the population at risk and the unit economic values used to value symptoms and statistical life (Pearce 1996). Overall the costs per capita consistently ranged from about US\$20-160. The main exception was for Bangkok where overall damages were estimated to be approximately US\$1000. With a $20 \%$ reduction in PM levels, overall damages would decrease to about US\$209, which would still be higher than the range exhibited by the other countries listed above.

Da Motta and colleague (1995) took an in depth look at the health costs associated with air pollution in Brazil, focussing on the major municipalities of Brazil, namely São Paulo, Rio de Janeiro, Belo Horizonte, and Cubatão. Health costs were calculated using a mortality rate curve for respiratory disease. The rate curve was developed from a exposure-response function that used a disease specific mortality incidence indicator for each year and municipality analyzed. Consequently this incidence indicator was used to estimate costs for hospitalizations and forgone output. Hospital costs reached some US\$785,000 for São Paulo, while for Rio de Janeiro and Cubatão, costs from hospitalizations did not exceed US\$151,000. These figures were stated in 1989 dollars. Foregone output due to lost working days was the highest for São Paulo with losses totaling US\$351,000 for São Paulo and US\$65,000 for Rio de Janeiro, and US\$71,000 for Cubatão (Da Motta and Mendes 1995).

Eskeland (1997) used a similar approach in his examination of the air pollution problem in Santiago, Chile. Morbidity was measured using workday equivalents as the denominator, and the days/hours lost to illness and average daily wage were used as the numerators. Mortality was measured using a exposure-response function of a $4.5 \%$ increase in total mortality for each $10 \mu \mathrm{g} / \mathrm{m}^{3}$ increase in PM10. This exposure-response function, based on previous acute mortality studies conducted both in and out of Santiago, was modified due to differences in pollution measures. Eskeland cautions the readers about generalizing, as any exposure-response function depends on particular conditions of the study in question, such as population characteristics, climate, and period. A linear exposure-response function may overestimate the relationship if the harvesting phenomenon is real, while any exposure-response curve may underestimate the relationship by it's failure to take into account chronic effects (Eskeland 1997).

\subsection{Willingness to Pay}

Taiwan was examined by Alberini and colleagues (1994) in valuing the health effects from air pollution by estimating the benefits of health improvement using a willingness to pay (WTP) approach. Through numerous interviews and surveys, the person was asked whether he would pay a stated amount to have avoided the illness altogether. WTP consists of three components: the value of disutility (discomfort) suffered while the individual is ill, the value of time lost while ill, and the amount he spends to relieve 
his discomfort. Overall, willingness to pay ranged from US $\$ 17$, for a cold that was a non Restricted Activity Day (RAD) and did not include a doctor's visit, to US $\$ 70$ for a non-cold that was a RAD and included a doctor's visit. On average, WTP is much higher for a one day episode than a five day episode. The authors concluded that the benefits estimated from air pollution abatement are transferable from US to Taiwan, but again they caution against generalizing the findings (Alberini et al. 1994).

\subsection{Loss of Welfare and Other Effects}

Estimating costs is a process laced with bias and assumptions as there is no single method of measuring health costs associated with air pollution. Da Motta and colleague (1995) take a very different approach from Pearce (1996) in estimating health costs even though both use an exposure-response function. However, neither makes reference to disability or loss of welfare caused by respiratory disease with regard to discomfort, pain, and other restrictions (Da Motta and Mendes 1995). They are difficult to account for mainly because they are difficult to measure and quantify. How does one measure the level of increased discomfort and/or pain? How does one quantify the extent to which his productivity has decreased due to the resultant adverse health effects of PM exposure? Days of work lost cannot be used to measure the degree of productivity that has been diminished if the person continues to go to work. Sorting out, defining and finally quantifying these nuances is a challenging and labor-intensive process. Additionally, there are other factors to take into consideration that could greatly impact the level of costs associated with air pollution, such as age at death. ARI occurs at a rate almost four times that of what is seen in developed countries, yet because society has not invested as much economically, via schooling and medical expenditures, the child's years life lost are counted as less than somebody in their 20 s. Since there are so many health endpoints associated with air pollution, it may be difficult to provide a comprehensive and all-inclusive assessment of the costs. In addition, as Da Motta and Mendes (1995) pointed out, it may be difficult to nigh near impossible to compute costs for issues such as loss of welfare. But in any case, these figures point out, that the costs incurred by health related air pollution are enormous, and those health effects are both costly and deadly.

\section{Gaps in Knowledge}

\subsection{Availability and Quality of PM Emissions Data}

TSP measurements have been used consistently in many of the epidemiological studies reviewed here to measure the association between health and air pollution, even though there is no hard evidence that it is TSP that is responsible for the health effects observed. What is hypothesized and has been more or less observed is a positive correlation between rising levels of fine particulates, and perhaps even ultrafine particulates. No one doubts any longer the fact that particulates have a deleterious effect on human health, but the magnitude of effects, what part of particulates stimulates the 
response and at what level is exposure to particulate matter safe, are all issues still under heated debate. TSP measurements are used primarily due to the ease of obtaining data, and consequently are used as a proxy for total exposure to PM. But is TSP really a good indicator of total exposure to particulate pollution?

Studies are beginning to show that ambient PM concentrations are not a good indicator of total exposure, and that for the most part it may underestimate personal exposure to particulate pollution. In addition, ambient concentrations are often used in developed countries as a proxy for total exposure. For areas where there are relatively few local emission sources of primary PM, this approach may not be an unreasonable assumption. But oftentimes in developing countries, one encounters a number of different sources that are specific to a certain locality and may influence personal exposure to a much greater degree than in developed countries. A number of people in developing countries use stoves for cooking and heating. This also determines the amount of PM emissions that people are exposed to on either a daily or even perhaps seasonal basis.

Furthermore the composition of the emissions will depend greatly on the type of fuel used in the cookstoves, which is also region specific. It depends on the natural resources that are available to the population in a certain area, and also the economic status of those people. Our livelihoods depend on the use of energy, but where we stand on the energy ladder is dependent on the country in which we live and our economic status within that community. Economic status matters to a much lesser degree in developed countries because the infrastructure is already in place. This is mirrored by the example of water. People in developing countries, in the lower socioeconomic status brackets will pay up to ten times more for potable water than people in the higher echelons of society. Once an infrastructure is put into place, the delivery of water to these households cost much less and the quality of water is normally much higher because it has been regulated. In developed countries, even the people in the lower income brackets are on the higher end of the energy ladder because the infrastructure has already been put in place, which is not the case in developing countries.

But if TSP is not an accurate indicator of total exposure, what should researchers use? There are financial limitations to doing research, which would make it impossible to attempt to assess personal exposure to particulate matter for each study. And for the most part, reports summarizing findings in other studies have converted TSP measurements to PM10 and PM10 to PM2.5 using conversions defined mostly by the USEPA. As a norm, PM10 is converted from TSP using a ratio of 0.55 taken from the USEPA. This relationship may not hold in developing countries where they have a greater amount of natural PM sources as well as a greater amount of anthropogenic PM sources.

\subsection{Synergistic Effects of Several Pollutants}

Lastly there is also speculation that PM may be acting as a surrogate for another toxic agent or a mix of toxic agents that may not be linearly related to PM. Doubts have arisen due to the non-linear relationship PM seems to exhibit with health effects at high concentrations. Hypotheses have been posed to account this curvilinear relationship, which have been explained at greater length above, such as harvesting or the idea of 
acting as a proxy for another toxic agent. Synergism or a co-pollutant effect may also be at work here, since animals studies have shown a possible synergistic relationship between $\mathrm{SO}_{2}$ and ozone in the rat, a species relatively insensitive to $\mathrm{SO}_{2}$ but fairly sensitive to ozone.

\subsection{Deficiencies in Studies}

\subsubsection{Dearth of Chronic Exposure Studies}

What one notices when examining all the available literature and data is that there has been an enormous effort in the area of assessing acute human health risk from acute exposure studies (epidemiological studies). There is a dearth of chronic exposure and health effects studies. The studies also tend to lack good exposure assessment. For the most part, the studies tend to be ecological in nature, really just taking a snap shot of the situation. However, it is believed that chronic exposures and the related health effects are extremely important. And epidemiological studies provide little information on biological mechanisms of particulate pollution.

\subsubsection{Provision for Additional Stress in Developing Countries}

Confounding elements are one of the leading problems in chronic health studies. They are extremely difficult to sort out and define. Overall, people in developing countries experience a greater degree of acute respiratory infections in children less than 5 years of age, and greater incidence of chronic respiratory illness. This has been observed in numerous developing countries (Ostro 1994). This may be due to baseline differences in demographics, behavior such as smoking habits or other competing risks, and factors related to income such as nutritional status, exercise and diet, occupational exposure, and the quality of health care, housing and supporting infrastructure (Ostro et al. 1996). These baseline differences may not confound the results in acute studies as much as in chronic studies. This is because it is believed that people will not vary in correlation with air pollution their personal habits or traits, such as smoking or access to healthcare so much in a short amount of time that it will confound the effects that one sees in acute mortality studies (Pope and Dockery 1996). But it could confound the effects to a greater degree in chronic studies, if issues such as smoking or exposure to ETS is present in the study population.

\subsubsection{Toxicological Studies}

Toxicological studies differ in the types of uncertainties they bring to the table. The types of biological responses observed after exposure to air pollution are very dependent upon the species used. Even though the dose may be well known in toxicological studies, which is exactly the opposite in epidemiological studies, it is still difficult to predict what exactly the health effects on humans will be. To what degree are we more sensitive than the most sensitive species? In addition to these difficult dilemmas, there is the additional problem of accurately trying to reproduce particulate matter. Particulate matter is a mixture of compounds, the chemical composition of which is 
contingent upon the source of pollution, transport and transformation in the atmosphere. Therefore can the results obtained in toxicological studies be used to make inferences about the possible health effects that one would observe in the human population? There is certainly a possibility that it could, and the possibility may increase with the hypothesis that toxicity may not depend uniquely upon the chemical composition, e.g., the acidity of particulate matter, but also the size of the particle. If part of the toxicity of PM stems from its size, it may account in part for why we in general see similar types of human health effects globally the magnitude of effects we see may differ from region to region.

\subsection{Validity of Extrapolating Data from Developed Countries}

The notion of extrapolating data from developed to developing countries has been proposed to compensate for the paucity of available data in developing countries. Ostro $(1994,1996)$ has done this for both Jakarta and Santiago, but admits that the estimated health effects are based on simple assumptions and broad averages. Also applying the exposure-response curves from the US or other developed country studies to developing countries adds additional uncertainty, because this assumes that the demographics are the same for the two countries, and that sensitive populations are also the same in those two countries. In addition it assumes that people's behaviors are similar as well, in that people spend the same proportion of time indoors and outdoors, and that they will respond to air pollution in a similar way. This then would require that indoor and outdoor pollution be similar to those in the comparative country, although much of the evidence disputes this fact (Ostro 1994, Ostro et al. 1996). This may account in part for the increased magnitude of effects one sees in developing countries as opposed to developed countries. Although Ostro and colleagues acknowledge the uncertainties associated with estimating health effects using data extrapolated from developed countries, others argue that it is not feasible to do so due to those uncertainties.

Cropper and colleagues (1997) looked at the health effect of air pollution in Delhi, taking a closer examination of the specific populations at risk for adverse health effects. It is hypothesized that at higher levels of air pollution, different populations become more susceptible and are thus affected. In Delhi, the impact of particulate matter on total non-trauma deaths is smaller than the effects found in the US. This may be due to the fact that in Delhi, a greater proportion of deaths occurs at younger ages and from causes not associated with air pollution which is not the case in the US. And the impacts of air pollution on deaths by age group may be very different in developing countries than in the US. In the US, peak effects occur among people 65 and older, and in Delhi, peak effects occur in the 15-44 age group, implying that a death associated with air pollution causes more life-years to be lost (Cropper et al. 1997).

Ostro's model used to estimate health effects and benefits due to air pollution is currently the most comprehensive and most commonly used by the air pollution community. The appropriate caveats should be applied though when using Ostro's approach, such as acknowledging the baseline differences that have not been accounted for, and the fact that each region will have different competing risks, which can ultimately affect the varying levels of health effects observed. 


\subsection{Costs of Air Pollution}

Even after the dilemma over how to estimate potential health effects from exposure to air pollution is resolved, next comes the issue of how to compare these estimates from one country or one region to the next. These are important issues to resolve if multilateral organizations, such as the WHO, UN or even World Bank, are to prioritize issues and regions to be funded for either further research or for aid.

No two examples of how to estimate cost of health benefits reviewed by this paper are identical and each uses a slightly different approach. The use of different approaches not only gives them different results, but in addition, it renders the results incomparable. And it has been mentioned, there has been little thought over how to compute costs associated with things like loss of welfare which includes pain, discomfort etc. Costs to society from loss of welfare and diminished productivity in the workplace may be expected to be enormous, and the ability to quantify these costs would illustrate more clearly how skewed the burden of ill health attributable to air pollution is over the world, and how great the costs from air pollution actually are. One that comes close perhaps is the Taiwan willingness to pay study, however, willingness to pay as a standard is very subjective, and people's willingness to pay may differ in each country depending upon values associated with work and sickness. Another reasonable method of estimation is to measure days of work lost by not going to work, although this provides an incomplete picture of loss of productivity and little if any information on the loss of welfare.

Thought should be given to use of different type of measurement to compare and assess health costs and benefits of air pollution and abatement strategies, respectively. A new measure of health has been proposed by researchers at the Harvard School of Public Health in conjunction with the WHO, namely the use of disability adjusted life years (DALYs) to measure the burden of disease all over the world. DALYs are calculated for each disease for a given population by summing losses from premature death, defined as the difference between actual age at death and life expectancy at that age in a low-mortality population and loss of healthy life resulting from disability (Murray et al. 1996). This would allow comparable measures of health costs or benefits to be quantified and compared across populations and regions of the world.

\section{Conclusion}

All evidence points to the fact that exposure to particulate matter is linked with premature mortality and certain morbidity endpoints. No one disputes this fact, but what is under discussion is to what extent are the effects seen attributable to PM, and how does this occur.

The human health effects of PM seen in both developed and developing countries are for the most part similar. It is reasonable to assume that magnification of health effects in developing countries are due to baseline health differences such as availability of medical care, nutrition, lack of infrastructure as well as higher PM levels. It is likely that environmental degradation and biological deterioration of the human body brought 
about by the factors listed above result in magnified levels of premature mortality and morbidity in developing countries.

There is increasing proof that the toxicity of particulate matter is at least in some way related to the size of the particle. This may be because the composition of the very fine particles tend to be more acidic or it may be because the ultrafine particles can penetrate and deposit deeper in the lungs by diffusional forces. Although the mechanisms for toxicity have not been defined, it seems clear that in general, adverse human health effects are more attributable to fine and ultrafine particles than the coarser and larger particle sizes.

The variation of total exposure, which may mostly occur indoors in developing countries, is reasonably well represented by variation in outdoor concentrations, and more so with fine PM. However, what has also been shown is that the absolute PM exposures are not well represented by ambient monitors. True exposures may be less or more, depending on indoor sources and housing type, but nevertheless different. Thus, even though the ambient monitoring gives us good exposure-response slopes, it cannot be used to accurately estimate impacts on human health. For assessing absolute risks one needs exposure studies, including indoor and/or personal monitoring, as well as slopes.

Extrapolation of data from developed countries to developing countries is reasonable, but baseline differences should be acknowledged and if possible accounted for. Exposure in developing countries is very different from developed countries. This is first of all due to the indoor sources, which seems to significantly affect exposure. Second the overall levels are higher, which can further influence indoor and outdoor exposure. Lastly one has to account for the difference in time spent outdoors and indoors. In addition baseline health status in developing countries is also very different. Having a lower health status can increase one's susceptibility to pollutants and contaminants, which is consequently why levels of COPD and ARI are so much higher in developing countries than in others. These differences are at the crux of why particulate matter is such a serious health problem in the developing countries. Total health impacts will ultimately be determined by local sources, therefore although total health impacts may not be able to be assessed, the RAINS model can, using Ostro's approach, estimate health effects due to outdoor air pollution.

Regrettably, much of the emphasis in health studies have been focussed on observable and quantifiable health effects, the most obvious being premature mortality. There is doubtless a number of other morbidity related health effects yet to be identified that contribute to majority of the burden of ill health attributable to particulate air pollution. This is most likely exemplified by the high level of disability in developing countries compared to developed countries. Much of the burden of ill health due to air pollution manifests in the form of respiratory infections, and chronic diseases such as COPD and COLD. Disability does not necessarily mean the loss of an arm, but can also mean a decrease in productivity through a general lack of well being. And the question that needs to be posed is how can this be defined and measured. One step that has been taken in this direction by researchers at Harvard and the WHO has been with the creation of DALYs. DALYs measure the burden of ill health for any given region in 
terms of life years lost from disability and premature death. This might allow policy makers to better quantify the costs of disability and loss of productivity to society, and even be able to compare them across populations and regions of the world. Other issues under discussion regarding the relationship between PM and health include to what extent are the effects seen attributable to PM, and how this occurs. 


\section{List of Abbreviations}

Health Related Terms:

$\begin{array}{ll}\text { ALRI } & \text { Acute Lower Respiratory Infection } \\ \text { ARI } & \text { Acute Respiratory Infection } \\ \text { COPD } & \text { Chronic Obstructive Pulmonary Disease } \\ \text { COHb } & \text { Carbon Monoxide Hemoglobin } \\ \text { CVD } & \text { Cardiovascular Disease } \\ \text { FEV } & \text { Forced Expiratory Volume } \\ \text { FVC } & \text { Forced Vital Capacity } \\ \text { LRI } & \text { Lower Respiratory Infection } \\ \text { OR } & \text { Odds Ratio } \\ \text { PHD } & \text { Pulmonary Heart Disease } \\ \text { RAD } & \text { Restricted Activity Day } \\ \text { URI } & \text { Upper Respiratory Infection }\end{array}$

Particulate Matter Terms:

PM Particulate Matter

$\mathrm{PM}_{10} \quad$ Particulate Matter with aerodynamic diameter $\geq 10 \mu \mathrm{m}$

$\mathrm{PM}_{(10-2.5)} \quad$ Particulate Matter with aerodynamic diameter between 10 and $2.5 \mu \mathrm{m}$

$\mathrm{PM}_{2.5} \quad$ Particulate Matter with aerodynamic diameter $\geq 2.5 \mu \mathrm{m}$

SPM Suspended Particulate Matter

TSP Total Suspended Particulates

Other Terms:

$\begin{array}{ll}\text { AMIS } & \text { Air Management Information System } \\ \text { DALY } & \text { Disability Adjusted Life Years } \\ \text { ETS } & \text { Environmental Tobacco Smoke } \\ \text { GEMS } & \text { Global Environmental Monitoring System } \\ \text { LPG } & \text { Liquified Petroleum Gas } \\ \text { PAH } & \text { Polycyclic (or: Polynuclear) Aromatic Hydrocarbons } \\ \mathrm{SO}_{2} & \text { Sulfur Dioxide } \\ \mathrm{UN}^{\mathrm{W}} & \text { United Nations } \\ \text { WHO } & \text { World Health Organization } \\ \text { WTP } & \text { Willingness To Pay }\end{array}$




\section{REFERENCES}

Alberini A, Cropper ML, Fu TT, Krupnick AJ, Liu JT, Shaw D, Harrington W. (1994) Valuing health effects of air pollution in developing countries: the case of Taiwan. Resources for the Future. Washington DC. Discussion Paper 95-01.

Amdur M. (1996) Animal toxicology. In Wilson R, Spengler J [eds.]. Particles in our Air: Concentrations and Health Effects. Harvard University Press. Boston, pp 85-120.

Awasthi, S, Glick HA, Fletcher RH, Ahmed N. (1996a) Ambient air pollution \& respiratory symptoms complex in preschool children. Indian J Med Res 104:257-262.

Awasthi S, Glick HA, Fletcher RH. (1996b) Effect of cooking fuels on respiratory diseases in preschool children in Lucknow, India. Am J Trop Med Hyg 55(1):48-51.

Azizi BHO, Zulkifli HI, Kasim MS. (1995) Indoor air pollution and asthma in hospitalized in children in a tropical environment. Journal of Asthma, 32(6):413-418.

Baek S, Kim YS, Perry R. (1997) Indoor air quality in homes, offices, and restaurants in Korean urban areas- indoor/outdoor relationships. Atmospheric Environment 31(4):529-544.

Bennett BG, Kretzschmar JG, Akland GG, de Koning HW. (1985) Urban air pollution worldwide. Environ. Sci. Tech., 19(4):298-304.

Borja-Aburto VH, Loomis DP, Bangdiwala SI, Shy CM, Rascon-Pacheco RA. (1997) Ozone, suspended particulates, and daily mortality in Mexico City. American Journal of Epidemiology, 145(3):258-68.

Chestnut LG, Vichit-Vadakan N, Ostro B, Smith KR, Tsai FC. (1998) Executive summary: health effects of particulate matter air pollution in Bangkok. World Bank.

Cifuentes LA, Lave LB. (1993) Economic valuation of air pollution abatement: benefits from health effects. Annual Rev. Energy Environ. 18:319-342.

China Energy Statistical Yearbook 1991 - 1996 (1998) Compiled by Department of Industrial and Transportation Statistics, State Statistical Bureau, People's Republic of China.

The Committee for the Analysis of PAHO Mission and Planning. (1998) The threefold way: A proposal for the Pan American Health Organization in Latin America.

University of California, Berkeley.

Cotton P. (1993) 'Best data yet' say air pollution below levels currently considered safe. Journal of the American Medical Association 269:3087-3088.

Cropper ML, Simon NB, Alberini A, Sharma PK. (1997) The health effects of air pollution in Delhi, India. World Bank: PRD Working Paper \#1860. 
Da Motta RS, Mendes APF. (1995) Health costs associated with air pollution in Brazil. Pricing the Planet Economic Analysis for Sustainable Development.

Daxiong Q, Yuqing M, Yingyun L, Qizhi W, Zhuliang Z. (1994) Household energy consumption in Beijing and Nanning, China. Energy Vol. 19, No 5, 529-538.

Dockery DW, Pope A, Xu X, Spengler JD, Ware JH, Fay ME, Ferris BG, Speizer FE. (1993) An association between air pollution and mortality in six U.S. cities. The New England Journal of Medicine, 329(24):1753-1759.

Eskeland GS. (1997) Air pollution requires multipollutant analysis: the case of Santiago, Chile. Amer. J. Agr. Econ, 79(5):1636-1641.

Ferin J, Oberdoster G, Penney DP. (1992) Pulmonary retention of ultrafine and fine particles in rats. Am J Respir Cell Mol Biol, 6:535-542.

Foster WM. (1999) Deposition and clearance of inhaled particles. In Holgate ST, Samet JM, Doren HS, Maynard RL [eds.]. Air pollution and health. Academic Press. London pp 295-324.

Health Council of the Netherlands. Committee on the Health Implications of Air Pollution (1995) Particulate air pollution. The Hague: Health Council of the Netherlands; publication no. 1995/14.

Janssen NAH, Hoek G, Brunekreef B, Harssema H, Mensink I, Zuidhof A. (1998) Personal sampling of particles in adults: relation among personal, indoor and outdoor air concentrations. American Journal of Epidemiology, 147(6):537-547.

Krupnick AJ. (1991) Urban air pollution in Developing countries: problems and policies. Resources for the Future. Washington DC. Discussion Paper QE91-14.

Krzyzanowski M, Schwela D. (1999) Patterns of air pollution in developing countries. In Holgate ST, Samet JM, Doren HS, Maynard RL [eds.]. Air pollution and health. Academic Press. London pp. 105-114.

Kyono H, Serita F, Toya T, Kubota H, Arito H, Takahashi M, Maruyama R, Homma K, Ohta H, Yamauchi Y, Nakakita M, Seki Y, Ishihara Y, Kagawa J. (1999) A new model rat with acute bronchiolitis and its application to research on the toxicology of inhaled particulate matter. Industrial Health, 37:47-54.

Li XY, Gilmour PS, Donaldson K, MacNee W. (1996) Free-radical activity and proinflammatory effects of particulate air pollution (PM10) in-vivo and in-vitro. Thorax, 51:1216-1222.

Lipfert FW. (1994) Air pollution and community health. Van Nostrand Reinhold. New York. 
Liu Q, Sasco AJ, Riboli E, Hu MX. (1993) Indoor air pollution and lung cancer in Guangzhou, People's Republic of China. American Journal of Epidemiology, 137:145154.

Luo RX, Wu B, Yi YN, Huang ZW, Lin RT. (1996) Indoor burning coal air pollution and lung cancer- a case -control study in Fuzhou, China. Lung Cancer,14(Suppl 1): S1130-S119.

MacNee W, Donaldson K. (1999) Particulate air pollution: Injurious and protective mechanisms in the Lungs. In Holgate ST, Samet JM, Doren HS, Maynard RL [eds.]. Air pollution and health. Academic Press. London, pp 653-672.

Malik SK. (1985) Cooking fuels and chronic respiratory disease. J Assoc Physicians India 33(5):378.

McMichael AJ, Smith KR. (1999) Seeking a global perspective on air pollution and health. Epidemiology 10(1), 5pp.

Mishra V, Retherford RD, Smith KR. (1997b) Effects of cooking smoke on prevalence of blindness in India. East-West Center Working Papers, Population series: No. 91.

Mishra V, Retherford RD, Smith KR. (1997c) Effects of cooking smoke on prevalence of tuberculosis in India. East-West Center Working Papers, Population series: No. 92.

Mumford JL, He XZ, Chapman RS, Cao SF, Harris DB, Li XM, Xian YL, Jiang WZ, $\mathrm{Xu}$ CW, Chuang JC, Wilson WE, Cooke M. (1987) Lung cancer and indoor air pollution in Xuan Wei, China. Science 235:217-220.

Murray CJL, Lopez AD (1996) The global burden of disease. Published by Harvard School of Public Health on behalf of the World Health Organization and the World Bank. Harvard University Press, Boston.

Nejedlý, Z, Campbell JL, Teesdale WJ, Dlouhy JF, Dann TF, Hoff RM, Brook JR, Wiebe HA (1998) Inter-Laboratory Comparison of Air Particulate Monitoring Data, J. Air \& Waste Manage. Assoc. 48:386-397.

Ostro B. (1994) Estimating the health effects of air pollutants: a method with an application to Jakarta. World Bank, Policy Research Working Paper 1301.

Ostro B. (1996) A methodology for estimating air pollution health effects. World Health Organization, Geneva. WHO/EHG/96.5.

Ostro BD, Eskeland GS, Feyziogly T, Sanchez JM. (1998) Air pollution and health effects: a study of respiratory illness among children in Santiago, Chile. World Bank: WPS 1932. 
Ostro B, Sanchez JM, Aranda C, Eskeland GS. (1996) Air pollution and mortality: results from a study of Santiago, Chile. Journal of Exposure Analysis and Environmental Epidemiology, 6(1):97-114.

Pearce D. (1996) Economic valuation and health damage from air pollution in the developing world. Energy Policy, 24(7):627-630.

Peng R, Wang L, Wang H, He K, Xu X. (1998) Indoor Air Pollution from Residential Energy Use in China. In McElroy MB, Nielsen CP, Lydon P [eds.]. Energizing China: Reconciling Environmental Protection and Economic Growth. Harvard University Press. Boston, pp.287-298.

Pereira LAA, Loomis D, Conceição GMS, Braga ALF, Arcas RM, Kishi HS, Singer JM, Böhm GM, Saldiva PHN. (1998) Association between air pollution and intrauterine mortality in São Paulo, Brazil. Environmental Health Perspectives, 106(6):325-329.

Peters A, Wichmann HE, Tuch T, Heinrich J, Heyder J. (1997) Respiratory effects are associated with the number of ultrafine particles. Am J Respir Crit Care Med, 155:1376-1383.

Pope CA, Dockery D. (1996) Epidemiology of chronic health effects: cross-sectional studies. In Wilson R, Spengler J [eds.]. Particles in our Air: Concentrations and Health Effects. Harvard University Press. Boston, pp.149-168.

Pope CA, Thun MJ, Namboodiri et al. (1995) Particulate air pollution as a predictor of mortality in a prospective study of U.S. adults. Am J Resp Crit Care Med, 151:669-674.

Qin Y et al. (1991) Indoor air pollution in four cities in China. Journal of Environment and Health, 8(3).

Rallis T. (1988) City transport in developed and developing countries. Macmillan, Basingstoke, Hamps., England.

Romieu I. (1999) Epidemiological studies of health effects arising from motor vehicle air pollution. In Schwela D, Zali O [eds.]. Urban Traffic Pollution. E\&FN Spon. London and New York, pp.9-70.

Romieu I, Meneses F Ruiz S, Sienra JJ, Huerta J, White MC, Etzel RA. (1996) Effects of air pollution on the respiratory health of asthmatic children living in Mexico City. Am J Respir Crit Care Med, 154:300-307.

Saldiva PHM, Lichtenfels AJFC, Paiva PSO, Barone IA, Martins MA, Massad E, Pereira JCR, Xavier VP, Singer JM, Böhm GM. (1994) Association between air pollution and mortality due to respiratory diseases in children in São Paulo, Brazil: A preliminary report. Environmental Research 65:210-225. 
Sato MIZ, Valent GU, Coimbrão CA, Coelho MCLS, Sanchez PS, Alonso CD, Martins MT. (1995) Mutagencity of airborne particulate organic material from urban and industrial areas of São Paulo, Brazil. Mutation Research, 335:317-330.

Seaton A, MacNee W, Donaldson K, Godden, D. (1995) Particulate air pollution and acute health effects. The Lancet, 345:176-178.

Seinfeld HJ, Pandis SN (1998) Atmospheric chemistry and physics: from air pollution to climate change. John Wiley \& Sons, Inc., New York.

Schwartz J, Marcus A. (1990) Mortality and air pollution in London: a time series analysis. American Journal of Epidemiology, 131:185-194.

Schwela DH. (1997) Cooking smoke: a silent killer. People and the Planet, 6(3):1-2.

Smith KR (1988) Air Pollution: Assessing total exposure in developing countries. Environm.ent 30(10):16-20 and 28-35.

Smith KR. (1993) Fuel combustion, air pollution exposure, and health: the situation in developing countries. Annu. Rev. Energy Environ. 18:529-566.

Smith KR. (1999) Indoor air pollution. Pollution Management in Focus, World Bank.

Smith KR, Apte MG, Yuqing M, Wongsekiarttirat W, Kulkarni A. (1994) Air pollution and the energy ladder in Asian cities. Energy, 19(5):587-600.

Spengler JD, Brauer M, Koutrakis P. (1990) Acid air and health. Environ. Sci. and Tech., 24(7):946-954.

Tarrasón L, Tsyro S (1998) Long-range transport of secondary particles, as presently estimated by the EMEP Langranian model. EMEP / MSC-W, Note 2/98.

Terblanche APS, Nel CME, Opperman L, Nyikos H. (1993) Exposure to air pollution from transitional household fuels in a South African population. Journal of Exposure Analysis and Environmental Epidemiology, 3(1):15-22.

The U.K. Department of the Environment (1993): Urban Air Quality in the United Kingdom. First Report of the Quality of Urban Air Review Group, London.

US-EPA. (1996) Air quality criteria for particulate matter. United States Environmental Protection Agency, Washington DC.

Wilson WE, Suh HH. (1997) Fine particles and coarse particles: concentration relationships relevant to epidemiologic studies. J Air \& Waste Manage Assoc, 47:12381249.

World Health Organization. (1995) Update and revision of the air quality guidelines for Europe. 
World Health Organization and United Nations Environment Programme. (1994) Air Pollution in the world's megacities. Environment 36(2):4-13, 25-37.

Woodruff TJ, Grillo J, Schoendorf KC. (1997) The relationship between selected causes of postneonatal infant mortality and particulate air pollution in the United States. Environmental Health Perspectives, 105:608-612.

Wu P, Cao S. (1987) Quality guaranty handbook of surrounding air monitoring, China, Environmental Science Press, Beijing, China.

Xu X. (1998) Air Pollution and Its Health Effects in Urban China. In McElroy MB, Nielsen CP, Lydon P [eds.]. Energizing China: Reconciling Environmental Protection and Economic Growth. Harvard University Press. Boston, pp.267-285

Xu X, Ding H, Wang X. (1995a) Acute effects of total suspended particles and sulfur dioxides on preterm delivery: a community based cohort study. Archives of Environmental Health. 50(6):407-415.

Xu X, Li BL, Huang HY. (1995b) Air pollution and unscheduled hospital outpatient and emergency room visits. Environmental Health Perspectives, 103:286-289.

Xu X, Dockery DW, Christiani DC, Baoluo L, Huang H. (1995c) Association of air pollution with hospital outpatient visits in Beijing. Archives of Environmental Health, 50(3):214-220.

Xu X, Gao J, Dockery DW, Chen Y. (1994) Air pollution and daily mortality in residential areas of Beijing, China. Archives of Environmental Health, 49(4):216-222.

Xu ZY, Blot WJ, Xiao HP. (1993) Smoking, air pollution, and the higher rates of lung cancer in Shenyang, China. Journal of the National Cancer Institute, 81(23):1800-1806.

Zhang J, Smith KR. (1996) Hydrocarbon emissions and health risks from cookstoves in developing countries. Journal of Exposure Analysis and Environmental Epidemiology, 6(2):147-161.

\section{Not Cited Background Documents}

Browne DR, Husni A, Risk MJ. (1999) Airborne lead and particulate levels in Semarang, Indonesia and potential health impacts. The Science of the Total Environment 227: 145-154.

De Francisco A, Morris J, Hall AJ, Armstrong Schellenberg JRM, Greenwood BM. (1993) Risk factors for mortality from acute lower respiratory tract infections in young Gambian children. International Journal of Epidemiology 22(6):1174-1182. 
Dockery DW, Pope A. (1996) Epidemiology of acute health effects: summary of timeseries studies. In Wilson R, Spengler J [eds.]. Particles in our Air: Concentrations and Health Effects. Harvard University Press. Boston, pp.123-147.

Dutt D, Srinivasa DK, Rotti SB, Sahai A, Donar D. (1996) Effect of indoor air pollution on the respiratory system of women using different fuels for cooking in an urban slum in Pondicherry. The National Medical Journal of India, 9(3):113-117.

Ezcurra E, Mazari-Hiriart M. (1996) Are Megacities viable? A cautionary tale from Mexico City. Environment, 38(1):6-35.

Flaschbart PG. (1999) Exposure to exhaust and evaporative emissions from motor vehicles. In Schwela D, Zali O [eds.]. Urban Traffic Pollution. E\&FN Spon. London and New York, pp.89-174.

Kodavanti UP, Costa DL. (1999) Animal models to study for pollutant effects. In Holgate ST, Samet JM, Doren HS, Maynard RL [eds.]. Air pollution and health. Academic Press. London pp165-198

Mishra V, Retherford RD. (1997a) Cooking smoke increases the risk of acute respiratory infection in children. National Family Health bulletin 8:1-4.

Monn C, Fuchs A, Högger D, Junker M, Kogelschatz D, Roth N, Wanner HU. (1997) Particulate matter less than 10um and fine particles less than 2.5um: relationships between indoor, outdoor and personal concentrations. The Science of the Total Environment, 208:15-21.

Pooley FD, Mille M. (1999) Composition of air pollution particles. In Holgate ST, Samet JM, Doren HS, Maynard RL [eds.]. Air pollution and health. Academic Press. London pp 619-634.

Pope CA, Dockery DW. (1999) Epidemiology of particle effects. In Holgate ST, Samet JM, Doren HS, Maynard RL [eds.]. Air pollution and health. Academic Press. London, pp.673-706.

Robin LF, Lees PSJ, Winget M, Steinhof M, Moulton LH, Santosham M, Correa A. (1996) Wood-burning stoves and lower respiratory illnesses in Navajo children. Pediatr Infect Dis $J, 15: 859-865$.

United Nations Economic and Social Council. (1999) Health risk from particulate matter from long range transboundary air pollution. Executive Body for the Convention on Long-Range Transboundary Air Pollution, EB.AIR/WG.1/1999/11.

Utell M, Samet J (1996) Airborne particles and respiratory disease: clinical and pathogenic considerations. In Wilson R, Spengler J [eds.]. Particles in our Air: Concentrations and Health Effects. Harvard University Press. Boston, pp. 169-188. 
Van Houdt JJ. (1990) Mutagenic activity of airborne particulate matter in indoor and outdoor environments. Atmospheric Environment, 24B(2):207-220.

Wang W, Ding H, Ryan L, Xu X. (1997) Association between air pollution and low birth weight: a community based study. Environmental Health Perspectives 105:514520.

Xu X, Wang LH. (1993) Association of indoor and outdoor particulate level with chronic respiratory symptoms in adult never-smokers. American Review of Respiratory Disease, 148:1516-1522. 


\section{Annex 1: Acute Mortality}

\begin{tabular}{|c|c|c|c|c|c|c|c|c|c|}
\hline Study Area & Reference & $\begin{array}{l}\text { Particulate Measure } \\
\qquad\left(\text { per } \bullet g /{ }^{m 3} \text { change }\right)\end{array}$ & $\begin{array}{l}\text { Measurement } \\
\text { Period }\end{array}$ & Mean TSP ${ }^{\mathrm{a}}$ & Mean PM10 & Total & Respiratory & CVD & Age $>65$ \\
\hline Bangkok & Chestnut et al 1998 & $\begin{array}{l}\text { PM10 } \\
\text { (per 30ug/m } \mathrm{m}^{3} \text { inc.) }\end{array}$ & 1992-1995 & & 65 & $3-5 \% * *$ & $7-20 \% * *$ & $2-5 \% * *$ & \\
\hline Beijing & Xu et al 1994 & TSP & 1989 & $\begin{array}{l}\text { east and west: } \\
375 \mathrm{ug} / \mathrm{m}^{3}\end{array}$ & & $4 \%$ & $38 \%(\mathrm{COPD}) * *$ & $8 \%$ (PHD) & \\
\hline Delhi & Cropper et al & $\begin{array}{l}\text { TSP } \\
\text { (per 100ug/m } / \mathrm{m}^{3} \text { inc.) }\end{array}$ & 1991-1994 & 375 & & $2.3 \% * *$ & $4.3 \% * *$ & $3.1 \% * *$ & \\
\hline \multirow[t]{3}{*}{ Mexico City } & $\begin{array}{l}\text { Borja-Aburto et al } \\
1997\end{array}$ & $\begin{array}{l}\mathrm{TSP}^{\mathrm{b}} \\
\text { (per 100ug/m change) }\end{array}$ & $1990-1992$ & 204 & & $6 \% * *$ & $9.5 \% * *$ & $5 \% * *$ & $6 \% * *$ \\
\hline & & $\begin{array}{l}\text { TSP or Temp (1 day lag) } \\
\text { (per } 100 \mathrm{ug} / \mathrm{m}^{3} \text { change) }\end{array}$ & & 204 & & $3 \%$ & & & $4.5 \% * *$ \\
\hline & & $\begin{array}{l}\text { TSP or Temp ( } 2 \text { day lag) } \\
\text { (per } 100 \mathrm{ug} / \mathrm{m}^{3} \text { change) }\end{array}$ & & 204 & & $2.4 \% * *$ & & & $1 \%$ \\
\hline Santiago & Ostro et al 1996 & $\begin{array}{l}\text { PM10 } \\
\text { (per } 115 \mathrm{ug} / \mathrm{m}^{3} \text { change) }\end{array}$ & 1989-1991 & $\begin{array}{l}210 \text { (ave for } \\
\text { three years) }\end{array}$ & $115 \mathrm{ug} / \mathrm{m}^{3}$ & $8 \% * *$ & $15 \% * *$ & $9 \% * *$ & $11 \% * *$ \\
\hline Sao Paulo & Saldiva et al 1994 & PM10 & $\begin{array}{l}\text { May 1990- } \\
\text { April 1991 }\end{array}$ & & 82.38 & \multicolumn{2}{|c|}{$\begin{array}{l}\text { mortality but non- significant } \\
\text { relation ship found w/PM10 }\end{array}$} & & \\
\hline Sao Paulo & Pareira et al 1998 & PM10 & $\begin{array}{c}\text { Jan 1991-Dec } \\
1992 \\
\end{array}$ & & 65,040 & \multicolumn{2}{|c|}{$\begin{array}{l}\text { Not signifcantly related to } \\
\text { intrauterine mort }\end{array}$} & & \\
\hline Shenyang & Xu ZY et al 1993 & $\begin{array}{l}\text { TSP } \\
\text { (per } 100 \mathrm{ug} / \mathrm{m}^{3} \text { inc) }\end{array}$ & 1992 & 430 & & $2 \%$ & $3 \%$ (COPD) & $2 \% * *$ & \\
\hline
\end{tabular}




\section{Annex 2: Acute Morbidity}

\begin{tabular}{|c|c|c|c|c|c|c|c|}
\hline Study Area & Reference & $\begin{array}{l}\text { Particulate Measure } \\
\text { (per } \bullet / \mathrm{m}^{3} \text { change) }\end{array}$ & $\begin{array}{l}\text { Measurement } \\
\text { Period }\end{array}$ & Mean TSP ${ }^{\mathrm{a}}$ & Mean PM10 & Health Endpoint & Details \\
\hline Bangkok & Chestnut et al 1998 & $\begin{array}{c}\text { PM10 } \\
\text { (per 30ug/m² inc.) }\end{array}$ & $1992-1995$ & & 65 & $\begin{array}{l}\text { Daily Hosp Adm } \\
\text { Respiratory } \\
\text { Cardiovascular } \\
\text { Resp Symptoms }\end{array}$ & $\begin{array}{l}5.5 \% * * \text { all ages year round } \\
11.1 \% * * \text { all ages non rainy } \\
17.6 \% * * \text { older adult year rd } \\
5.3 \% * * \text { all ages year round } \\
7.6 \% * * \text { older adult year rd } \\
26 \% * * \text { adult upper } \\
20 \% * * \text { adult lower } \\
9 \% * * \text { children upper } \\
7 \% * * \text { children lower } \\
9 \% * * \text { Nurses upper } \\
5 \% * * \text { Nurses lower }\end{array}$ \\
\hline Beijing & Xu et al $1995 b$ & $\begin{array}{c}\text { TSP } \\
\text { (per 100ug/m } / \mathrm{m}^{3} \text { increase) }\end{array}$ & 1991 & 441 & & Daily Hosp Adm & $6 \% * *$ \\
\hline Beijing & Xu et al 1995a & $\begin{array}{c}\text { TSP } \\
\text { (per 100ug/m }{ }^{3} \text { inc.) }\end{array}$ & 1988 & $375 \mathrm{ug} / \mathrm{m}^{3}$ & & preterm birth & $10 \% * *$ \\
\hline Beijing & Xu et al 1991 & TSP & 1986 & $\begin{array}{l}\text { ind: } 261 \mathrm{ug} / \mathrm{m}^{3} \\
\text { resid: } 389 \mathrm{ug} / \mathrm{m}^{3} \\
\text { sub: } 449 \mathrm{ug} / \mathrm{m}^{3}\end{array}$ & & $\begin{array}{l}\text { FEV } \\
\text { FVC }\end{array}$ & $\begin{array}{l}131.4 \mathrm{ml} \text { reduction } \\
478.7 \mathrm{ml} \text { reduction }\end{array}$ \\
\hline Beijing & Xu et al 1995c & $\begin{array}{c}\text { TSP } \\
(\% \text { increase btwn least } \\
\& \text { most polluted days })\end{array}$ & 1990 & 388 & & $\begin{array}{l}\text { Nonsurgery visits } \\
\text { Pediatrics } \\
\text { Internal medicine }\end{array}$ & $\begin{array}{l}17 \% * * \\
29 \% * * \\
26 \% * *\end{array}$ \\
\hline Beijing & Wang et al 1997 & TSP & $1988-1991$ & $\begin{array}{l}\text { third quintile } \\
361-437 \mathrm{ug} / \mathrm{m}^{3}\end{array}$ & & low birth weight & $10 \% * *$ \\
\hline
\end{tabular}


Acute Morbidity, continued

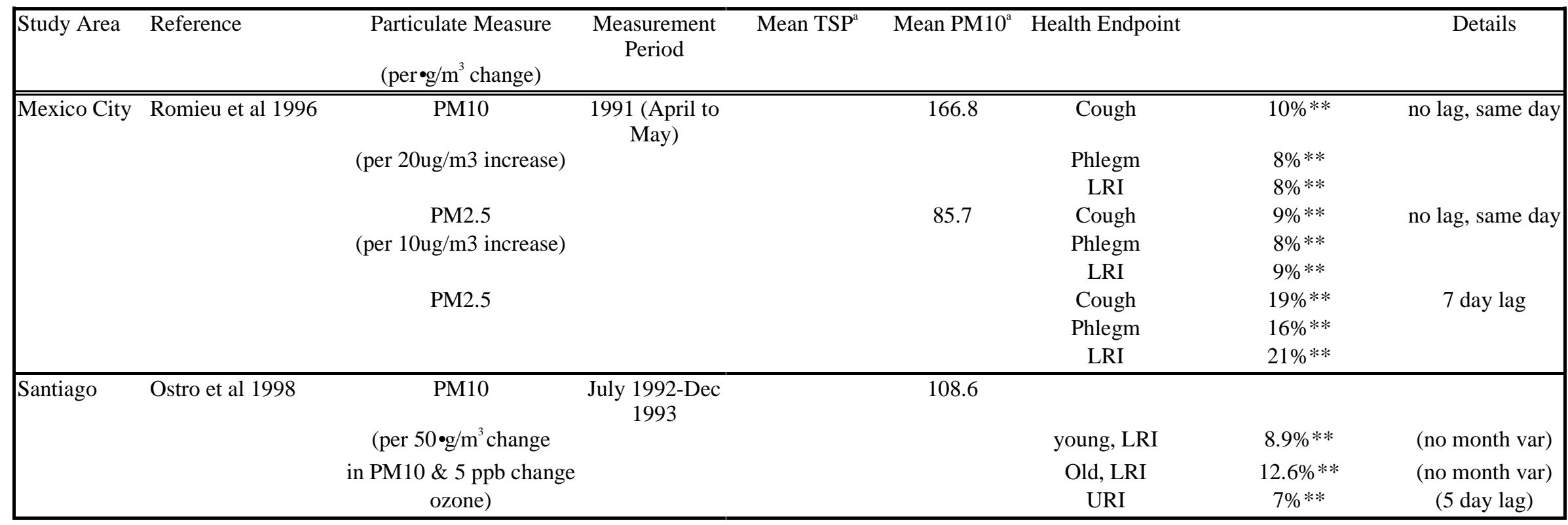




\section{Annex 3: Chronic Health Effects}

\begin{tabular}{|c|c|c|c|c|c|c|c|}
\hline Study Area & Reference & $\begin{array}{l}\text { Particulate Measure } \\
\left(\text { per } \bullet / \mathrm{m}^{3} \text { change) }\right.\end{array}$ & Measurement Period & Mean TSP ${ }^{\mathrm{a}}$ & Mean PM10 ${ }^{a}$ & Health Endpoint & \\
\hline Beijing & Xu et al 1993 & TSP & 1981-1985 & $\begin{array}{l}\text { low: } 261 \mathrm{ug} / \mathrm{m} 3 \\
\text { med: } 389 \mathrm{ug} / \mathrm{m} 3 \\
\text { high: } 449 \mathrm{ug} / \mathrm{m} 3\end{array}$ & & $\begin{array}{c}\text { Wheeze } \\
\text { Wheeze } \\
\text { w/breathlessness } \\
\text { All symptoms }\end{array}$ & $\begin{array}{l}2.1^{* *} \\
2.5^{* *} \\
1.8^{* *}\end{array}$ \\
\hline Fuzhou (China) & Luo et al 1996 & $\begin{array}{c}\text { Risk Factors such as } \\
\text { Indoor Air Pollution } \\
\text { Smoking } \\
\text { Exposure to ETS }\end{array}$ & 1990-1991 & & & Lung Cancer & $\begin{array}{c}\text { OR } \\
7.6^{* *} \\
2.7^{* *} \\
2.4^{* *}\end{array}$ \\
\hline Guangzhou & Liu et al 1993 & $\begin{array}{l}\text { Risk Factors such as } \\
\text { cooking in living area }\end{array}$ & 1983-1984 & & & $\begin{array}{c}\text { Lung Cancer } \\
\text { Men } \\
\text { Women } \\
\end{array}$ & $\begin{array}{c}\mathrm{OR} \\
2.4^{* *} \\
5.9^{* *} \\
\end{array}$ \\
\hline Shenyang & Xu ZY et al 1993 & TSP & 1992 & $\begin{array}{l}\text { low: } 361 \mathrm{ug} / \mathrm{m} 3 \\
\text { med: } 477 \mathrm{ug} / \mathrm{m} 3 \\
\text { high: } 518 \mathrm{ug} / \mathrm{m} 3\end{array}$ & & Total Mortality & $\begin{array}{c}177 / 100,000 \\
\text { increase for } \\
\text { 100ug/m3 increase } \\
\text { in TSP }\end{array}$ \\
\hline Xuan Wei & Mumford et al 1987 & $\begin{array}{l}\text { Type of coal used } \\
\text { smoky }(\mathrm{CG})^{\mathrm{b}} \\
(\mathrm{LB})^{\mathrm{c}} \\
(\mathrm{RS})^{\mathrm{d}} \\
{\text { smokeless }(\mathrm{CG})^{\mathrm{b}}}^{(\mathrm{RS})^{\mathrm{d}}}\end{array}$ & $\begin{array}{c}1973-1979 \text { mortality } \\
1983 \text { msmts } \\
1 \text { home } \\
4 \text { homes }\end{array}$ & $\begin{array}{c}24,400 \\
9,500 \\
22,300 \\
1,800 \\
1,100\end{array}$ & & Lung Cancer & $\begin{array}{c}\text { Mortality/100,000 } \\
151.8 \\
109.3 \\
93\end{array}$ \\
\hline
\end{tabular}




\section{Annex 4: Indoor Pollution}

\begin{tabular}{|c|c|c|c|c|c|}
\hline Study Area & Reference & Exposure & Health Endpoint & Measurement & Details \\
\hline Rural Gambia & De Francisco et al 1993 & Presence of indoor air pollution & 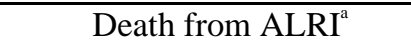 & $\overline{\mathrm{O}} \mathrm{OR}=5.2 * *$ & \\
\hline India & Malik 1985 & $\begin{array}{l}\text { Type of cookstove } \\
\text { Chulla cowdung cakes \& fire wood } \\
\text { Kerosene stove and Angithi coal } \\
\text { Kerosene stove } \\
\text { Gas cooking }\end{array}$ & $\begin{array}{l}\text { Chronic bronchitis \& } \\
\text { Airways obstruction }\end{array}$ & $\begin{array}{l}5.00 \% \\
2.56 \% \\
1.30 \% \\
1.55 \%\end{array}$ & \\
\hline India & Mishra et al 1997a & $\begin{array}{l}\text { Biomass fuels cookstove } \\
\text { Cleaner fuels cookstove }\end{array}$ & Acute respiratory infection & $\begin{array}{c}69^{* *} \\
53\end{array}$ & $\begin{array}{l}\text { Adjusted } \mathrm{ARI}^{\mathrm{b}} \text { rate } \\
\text { per } 1,000 \text { children }\end{array}$ \\
\hline India & Mishra et al $1997 b$ & Type of cookstove & $\begin{array}{c}\text { Partial Blindness } \\
\text { Partial or complete } \\
\text { blindness }\end{array}$ & $\begin{array}{l}\mathrm{OR}=1.34 * * \\
\mathrm{OR}=1.32 * *\end{array}$ & \\
\hline India & Mishra et al 1997c & Type of cookstove & Tuberculosis & $\mathrm{OR}=3.81 * *$ & \\
\hline $\begin{array}{l}\text { Indian urban slum } \\
\text { Kusumpur } \\
\text { Kathputly } \\
\text { (high pollution area) }\end{array}$ & Sharma et al 1998 & $\begin{array}{l}\text { Type of cookstove } \\
\text { Wood } \\
\text { Kerosene } \\
\text { Wood } \\
\text { Kerosene }\end{array}$ & bronchiolitis & $\begin{array}{l}22.50 \% \\
27.10 \% \\
13.70 \% \\
12.10 \%\end{array}$ & \\
\hline Kuala Lumpur & Azizi et al 1995 & Presence of woodstove & Asthma & $\mathrm{OR}=1.4$ & not significant \\
\hline Lucknow & Awasthi et al 1996a & $\begin{array}{l}\text { SPM } \\
\text { Risk factors: } \\
\text { Being indoors while cooking }\end{array}$ & $\begin{array}{c}\text { Respiratory } \\
\text { Symptoms Complex }\end{array}$ & $\begin{array}{l}\mathrm{OR}=1.24 * * \\
\mathrm{OR}=2.04 * *\end{array}$ & \\
\hline Lucknow & Awasthi et al 1996b & $\begin{array}{l}\text { Type of cooking fuel } \\
\text { Dung cakes }\end{array}$ & Respiratory disease & $\mathrm{OR}=2.69 * *$ & \\
\hline Pondicherry & Dutt et al 1996 & Type of cookstove & FVC, FEV, FEV\% & $\begin{array}{l}\text { biofuel users e } \\
\text { respiratory sym } \\
\text { significantly lo } \\
\text { than kerosene }\end{array}$ & $\begin{array}{l}\text { perience more } \\
\text { toms and } \\
\text { ver lung function } \\
\text { LPG users }\end{array}$ \\
\hline
\end{tabular}


